Review

\title{
Therapeutic Associations Comprising Anti-PD-1/PD-L1 in Breast Cancer: Clinical Challenges and Perspectives
}

\author{
Fanny Ledys ${ }^{1,2,3, \dagger}$, Laura Kalfeist ${ }^{1,2,3, \dagger}$, Loick Galland ${ }^{1,4}$, Emeric Limagne ${ }^{1,2,3, \ddagger}$ and Sylvain Ladoire ${ }^{1,2,3,4, *, \ddagger}$ \\ 1 Platform of Transfer in Cancer Biology, Georges-François Leclerc Center, 21000 Dijon, France; \\ fledys@cgfl.fr (F.L.); lkalfeist@cgfl.fr (L.K.); lgalland@cgfl.fr (L.G.); elimagne@cgfl.fr (E.L.) \\ 2 School of Medicine and Pharmacy, University of Burgundy Franche-Comté, 21000 Dijon, France \\ 3 UMR INSERM 1231, Lipides Nutrition Cancer, 21000 Dijon, France \\ 4 Department of Medical Oncology, Georges-François Leclerc Center, 21000 Dijon, France \\ * Correspondence: sladoire@cgfl.fr \\ + These authors contributed equally. \\ $\ddagger$ Senior author.
}

check for updates

Citation: Ledys, F.; Kalfeist, L.; Galland, L.; Limagne, E.; Ladoire, S. Therapeutic Associations Comprising Anti-PD-1/PD-L1 in Breast Cancer: Clinical Challenges and Perspectives. Cancers 2021, 13, 5999. https:/ / doi.org/10.3390/cancers13235999

Academic Editor: Andrea Cavazzoni

Received: 18 October 2021

Accepted: 19 November 2021

Published: 29 November 2021

Publisher's Note: MDPI stays neutral with regard to jurisdictional claims in published maps and institutional affiliations.

Copyright: (c) 2021 by the authors. Licensee MDPI, Basel, Switzerland. This article is an open access article distributed under the terms and conditions of the Creative Commons Attribution (CC BY) license (https:// creativecommons.org/licenses/by/ $4.0 /)$.
Simple Summary: Breast cancer remains the leading cause of death in women. Despite improved treatment in recent years, new therapeutic options are still needed for some types of breast cancer. In view of the poor response of breast cancer to immunotherapy, it is important to develop therapeutic combinations in order to sensitize breast tumors to anti-PD-(L)1 immunotherapy. This review presents the different combinations developed in pre-clinical and clinical studies according to the immune characterization of breast cancers.

\begin{abstract}
Despite a few cases of long-responder patients, immunotherapy with anti-PD-(L)1 has so far proved rather disappointing in monotherapy in metastatic breast cancer, prompting the use of synergistic therapeutic combinations incorporating immunotherapy by immune-checkpoint inhibitors. In addition, a better understanding of both the mechanisms of sensitivity and resistance to immunotherapy, as well as the immunological effects of the usual treatments for breast cancer, make it possible to rationally consider this type of therapeutic combination. For several years, certain treatments, commonly used to treat patients with breast cancer, have shown that in addition to their direct cytotoxic effects, they may have an impact on the tumor immune microenvironment, by increasing the antigenicity and/or immunogenicity of a "cold" tumor, targeting the immunosuppressive microenvironment or counteracting the immune-exclusion profile. This review focuses on preclinical immunologic synergic mechanisms of various standard therapeutic approaches with anti-PD-(L)1, and discusses the potential clinical use of anti-PD-1/L1 combinations in metastatic or early breast cancer.
\end{abstract}

Keywords: breast cancer; PD-1/PD-L1 blockade; immune response; chemotherapies; kinase inhibitors; targeted therapies

\section{Background and Current Development of Immunotherapy with Anti-PD-1/PD-L1 in Breast Cancer}

According to the latest global cancer statistics (GLOBOCAN 2020), breast cancer (BC) ranks among the most frequently encountered cancers, with a rate of $11.7 \%$. BC accounted for $6.9 \%$ of cancer deaths in 2020, making it the leading cause of cancer death in women worldwide [1]. BC has traditionally been classified into three subtypes associated with different prognosis and substantial microenvironment heterogeneity. Among these subsets, luminal cancers are characterized by estrogen (ER) + / - progesterone receptor (PR) expression. Conventional systemic treatment (both in the adjuvant and metastatic setting) is based on hormone therapy, and prognosis is relatively good. The second type, called HER2-positive BC, is characterized by high expression of this receptor and does 
not express hormone receptors, and is treated with HER2-targeted therapies, most often in combination with chemotherapy. Finally, the third type is triple-negative BC (TNBC), which is characterized by the absence of expression of any of the three predictive markers (i.e., ER, PR or HER2). Therefore, there is currently no specific targeted therapy for this subtype, and chemotherapy remains the standard of systemic treatment, always in the adjuvant or metastatic setting. The latter two types of cancer have a poor prognosis [2].

Tumor-mediated immune escape is one of the hallmarks of cancer that blunts cancer cell detection and elimination by cytotoxic lymphocytes. This phenomenon implicates a large number of biological processes, and one of them is immune checkpoint induction, such as cytotoxic T-lymphocyte-associated protein 4 (CTLA-4) or PD-1, which have suppressive functions against activation of anti-tumor lymphocytes. Blockade of these immune checkpoints by monoclonal antibodies has positively impacted the therapeutic management of a broad number of malignancies, by enabling profound and lasting tumor responses to be obtained, albeit in a small subset of patients [3].

Historically, BC was not considered to be immunologically active, especially compared to other tumors such as melanoma, renal or lung cancers [4,5], most often due to an "immunologically cold" contexture, associating low immune cell infiltration (in particular, cytotoxic T lymphocytes), and low tumor mutational burden (TMB). This is especially true for HER2 negative luminal tumors, which account for the overwhelming majority of breast cancers [6].

Nevertheless, there is mounting evidence that some BCs can present a more favorable immune biology, with a high level of tumor infiltrating lymphocytes (TILs). This infiltration is associated with better prognosis and also has a positive predictive impact on chemosensitivity, particularly in the context of neoadjuvant chemotherapy, where higher TIL level is associated with higher probability of pathological complete response (pCR) $[7,8]$. However, this prognostic and predictive impact of the efficacy of chemotherapy depends on the breast cancer subtype, and is particularly marked in the triple negative and HER2 positive subtypes, in which there is more often a higher TMB, as well as greater inflammatory signature expression. Moreover, in the HER2 positive subtype, the immune response (in particular TIL levels) also seems to influence the effectiveness of anti-HER2 treatments, in particular monoclonal antibodies (possibly by the phenomenon of Antibody-Dependent Cell Cytotoxicity (ADCC)) [7,9-11]. Among TILs, the presence of CD8 ${ }^{+} \mathrm{T}$ cells, as well as the ratio between effector $\mathrm{CD}^{+}$and regulatory $\mathrm{FoxP}^{+} \mathrm{T}$ cells, appears to be associated with both better prognosis and long-term survival $[7,12,13]$. T cells infiltration is variable between different breast cancer subtypes. Indeed, TNBC and HER2 positive tumors appear to be the most $\mathrm{CD} 8^{+} \mathrm{T}$ cells infiltrated with a median percentage of patients with high $\mathrm{CD}^{+} \mathrm{T}$ cells levels of $60 \%$ and $61 \%$ respectively compared to the $\mathrm{RH}+$ subtype with $43 \%$. Furthermore, $70 \%$ and $67 \%$ of TNBC and HER2 patients had high levels of FoxP3+ T cells compared to $38 \%$ of $\mathrm{HR}+$ patients $[14,15]$.

These observations suggest that therapeutic strategies based on cytotoxic immune cell stimulation and/or immunosuppression blockade can be effective for BC treatment. Among these strategies, the discovery of immune checkpoints, which regulate immune activation, and their blockade with monoclonal antibodies targeting PD-1/PD-L1, has been considered and tested.

The first studies were carried out with anti PD-(L)1 monotherapy in patients with advanced metastatic disease, and TNBC (supposed to be more immunogenic). Initial studies carried out with atezolizumab (anti PD-L1) or pembrolizumab (anti-PD-1) as monotherapy and in advanced stage, found objective response rates (ORR) around 20\% (including in patients with PD-L1 negative tumors), with long-lasting tumor responses in some patients [16,17]. The mechanisms behind these very low response rates are still largely unknown. Like other tumor types, certain breast cancer tumor cells are, for example, capable of co-expressing PD-1 and PD-L1, which slows down tumor growth. Targeting PD-1 or PD-L1 is then paradoxically able to stimulate tumor growth. Whether this mecha- 
nism could explain the poor results of anti-PD-1 or anti PD-L1 monotherapy remains an unanswered question [18].

Higher ORRs were observed in patients treated in first line, especially if the tumor expressed PD-L1 and if a higher level of TIL infiltration was observed [19]. In the various cohorts of the Keynote 086 study (phase II), pembrolizumab monotherapy made it possible to obtain higher response rates in patients with PD-L1 positive tumors, in the first line of treatment (ORR: $23 \%$, with $4 \%$ achieving complete response), compared to patients who had already received chemotherapy, and not selected for tumor PD-L1 status (ORR: $4.7 \%$ ) [20]. These first results, suggesting a greater benefit during early use, and when the tumor expresses PD-L1 by immunohistochemistry, were confirmed in the phase III Keynote 119 study, in which pembrolizumab monotherapy was used in second or third line of metastatic TNBC treatment, without better ORR as compared to single-agent chemotherapy. A significant increase in survival was nevertheless seen for patients with higher tumoral PD-L1 expression [21]. Beyond mTNBC, avelumab, an anti-PD-L1, has been used as monotherapy in patients with different subtypes of metastatic breast cancer, and yielded an ORR of $2.8 \%$ for ER+/HER2 - tumors, but no response in HER2 positive tumors (compared to an ORR of $5.2 \%$ in patients with mTNBC) [22].

These first results, therefore, seem to indicate that a small group of patients (difficult to identify due to imperfect selection biomarkers) with metastatic breast cancer (and not only of the TNBC subtype), may benefit from therapeutic approaches by ICB (immune checkpoint blockade) monotherapy, but also that it is necessary to develop therapeutic strategies in order to increase the number of responding patients. Thus, concerted efforts have been made to better understand the mechanisms responsible for defects in spontaneous immune response against $\mathrm{BC}$, and how to make it more efficient from a therapeutic point of view, in order to rationally combine ICB with other treatments.

Many treatments used in oncology are indeed capable of inducing immunogenic cell death (ICD) [23,24]. ICD is a mode of drug-induced cell death characterized by molecular hallmarks including the release of damage-associated molecular patterns (DAMPs) by dying cancer cells [25]. ICD can initiate efficient antitumor immunity, and thus augment the therapeutic effect of a given cytotoxic drug [26]. Besides this effect, some commonly used chemotherapies also appear able to modulate the tumor immune microenvironment quantitatively or qualitatively, influence antigen presentation or release of tumor antigens or chemokines, or are capable of remodeling the tumor stroma in a manner more favorable to immune cell trafficking [27]. Since many chemotherapy drugs are able to act at these different levels, and chemotherapy is part of the usual treatments for localized or metastatic breast cancer, numerous studies involving ICB+ chemotherapy have been performed, in TNBC and other subtypes.

Initial phase I-II trials testing combinations involved chemotherapies usually used for the treatment of metastatic breast cancer (MBC), in particular nab-paclitaxel [28], or eribulin mesylate [29], and clearly showed higher response rates (26-39\%) than monotherapy with ICB, whether in the first or second line, again with lasting tumor response. Following these encouraging results, several randomized phase III trials were performed to confirm the value of adding anti-PD(L)-1 treatment to first-line chemotherapy in metastatic TNBC (mTNBC). However, currently available results from these studies are conflicting: the IMpassion 130 trial (NCT02425891), which randomized patients to nab-paclitaxel vs nabpaclitaxel + atezolizumab as first-line treatment for $\mathrm{mTNBC}$, showed a significant benefit in terms of PFS in the overall population, but also an especially marked benefit in patients with a PD-L1 positive tumors (7.5 vs. 5.0 months, $p<0.001$ ) [30]. A benefit in OS was not shown in the overall population, but an exploratory analysis in the PD-L1 positive population highlighted a median OS of 25 months in the atezolizumab group, compared to 15.5 months in the placebo group. These results contrast with those from the IMpassion 131 trial (NCT03125902), in which mTNBC patients were randomized between paclitaxel and paclitaxel + atezolizumab, with no advantage in terms of OS or PFS for patients receiving anti PD-L1 [31]. These results are particularly intriguing, and remain unexplained, 
especially since a third study (Keynote-355, NCT02819518) conducted in the same type of patient (first-line treatment of $\mathrm{mTNBC}$ ) reported a clinically meaningful improvement in PFS among patients treated with pembrolizumab in combination with chemotherapy (nab-paclitaxel, paclitaxel or gemcitabine-carboplatin) [32], compared to chemotherapy alone. The pembrolizumab benefit was seen especially in patients whose tumor expressed significant levels of PD-L1 by IHC (CPS score $\geq 10$ ) (median PFS 9.7 vs. 5.6 months). Interestingly, in this study, patients treated with paclitaxel + pembrolizumab seemed to benefit as much from ICB as those who received nab-paclitaxel + pembrolizumab, compared to patients treated with the same chemotherapies plus placebo. The reasons for these discordant results between phase III trials are not fully understood, and the results of other first-line studies incorporating ICB in association with standard of care are eagerly awaited (e.g., the IMpassion 132 trial NCT03371017 in mTNBC, or NCT03199885 in HER2+ BC). In this review, we will discuss some hypotheses that may explain these differences from an immunological point of view.

Taking into account immunosuppressive load, and tumor clonal heterogeneity, probably at a lower level as compared to metastatic disease, it would be expected to obtain deeper tumor responses in early breast cancer $(\mathrm{eBC})$ with chemotherapy + ICB. As the efficacy of neoadjuvant chemotherapy (NAC) can be evaluated by pathologic complete response $(\mathrm{pCR})$ in $\mathrm{eBC}$, many clinical trials have evaluated the combination of chemotherapy + ICB in this setting. Earliest phase Ib studies, like Keynote 173 [33] showed impressive pCR rates of around $60 \%$ in PD-L1 unselected eTNBC patients. Higher pretreatment expression of PDL1, and stromal TIL levels were significantly associated with higher PCR rates. I-SPY 2 is a phase II trial platform that is evaluating novel neoadjuvant agents on top of a classical NAC backbone of taxane/anthracycline, with pCR estimation by Bayesian models. With this approach, combining pembrolizumab with NAC made it possible to triple $\mathrm{pCR}$ probability not only in eTNBC (60\% vs. $20 \%$ ), but also in ER+/HER2- eBC (34\% vs. 13\%) [34]. These encouraging results have prompted larger randomized trials comparing NAC to NAC + ICB in eBC. In the phase II GeparNuevo trial [35], surprisingly, there was no difference in pCR between patients treated with NAC alone and NAC + durvalumab, except in those with a short run-in of durvalumab monotherapy before NAC + ICB (pCR: $61 \%$ vs. $44.2 \%$ in the placebo arm). These results highlight the need to better understand how to sequence ICB with chemotherapy, and to discover the optimal "immunologic window" in which to use immunotherapy during the treatment course. Of note, after extended follow-up, patients treated with durvalumab had better 3-year survival (distant-DFS, and OS) [36]. More recently, 2 phase III randomized trials clearly indicated a significant benefit of adding anti-PD-(L)1 to NAC for the treatment of eTNBC: in the IMpassion 031 trial, an absolute pCR increase of $17 \%$ was observed in patients randomized to the atezolizumab + NAC arm, compared to NAC alone (58\% vs. 41\%) [37]. In the Keynote 522 trial, patients treated with $\mathrm{NAC}+$ pembrolizumab had a $\mathrm{pCR}$ rate of $65 \%$, significantly higher than in patients who received NAC only (51\%) [38]. Interestingly, in these two positive studies, PD-L1 tumor expression was not predictive of ICB benefit, but was associated with a higher probability of achieving pCR, both with ICB + NAC, and with NAC alone. In contrast, in a third study called neoTRIP [39], no difference in pCR was observed between patients treated with NAC alone, and those treated with NAC + atezolizumab. An explanation for these apparently contradictory results could be the nature of the chemotherapy backbone, which comprised anthracyclines (sequenced with taxane +/- carboplatin) in IMpassion 031 and Keynote 522 , but not in neoTRIP (paclitaxel + carboplatin). Given the differences in immunological properties of these drugs, which we will discuss in this review, these clinical results highlight the importance of considering the therapeutic partners of ICB from an immunological perspective. In eTNBC, many other large clinical trials evaluating PD-(L)1 blockade are ongoing, in the neoadjuvant setting (like NSABP B-59 NCT03281954), the adjuvant setting (Impassion 030 NCT03498716), or in post-neoadjuvant high risk patients with post-NAC residual disease (SWOG S1418/BR006 (NCT02954874), A-Brave (NCT02926196). The same 
neoadjuvant strategy incorporating pembrolizumab with standard NAC is also being explored in high risk ER+/HER2- eBC patients in the Keynote 756 study (NCT03725059).

Several lessons can be learned from these clinical and biological results. First, concerning the predictive value of PD-L1 status, all these studies show that it is not the perfect biomarker for predicting the benefit of immunotherapy. Moreover, while increased expression of PD-L1 makes it possible to select a population who probably benefit more from immunotherapy (in monotherapy or in combination with chemotherapy compared to chemotherapy alone), on the other hand in early stage disease (neoadjuvant setting), PD-L1 expression is probably linked to intra-tumoral immune response and TIL infiltration, which is a prognostic and predictive factor for chemotherapy efficacy. In TNBC, the differences in the efficacy of chemotherapy + immunotherapy combinations between localized and metastatic stages are probably partially explained by the immunosuppressive load, and increasing tumor heterogeneity with more advanced disease stage, [40-42]. Moreover, metastatic spread could also reflect escape from immune surveillance at the primary tumor site, and thus, the presence of immunoselected disease that may be less sensitive to immunotherapeutic approaches [43]. As "hot" immunogenic BC components are usually more chemo-sensitive, the metastatic disease is probably also enriched in "cold" tumor clones, previously selected by initial chemotherapy. For metastatic patients, the predictive value of PD-L1 expression is also partly related to the presence of an anti-tumor immune response, and suggests that it is essential to use therapeutic partners capable of converting a cold and/or immunosuppressed tumor microenvironment into a hot, activated immune context, in order to sensitize the tumor to PD-1 blockade. However, considering the immunological properties of paclitaxel (the most widely used first-line treatment in mTNBC), it is unlikely that this drug class is the best companion for immunotherapy in BC. Indeed, preclinical and human data have shown that paclitaxel is not a strong ICD inducer and has a limited effect on selective depletion/inhibition of immunosuppressive cells [27,44]. In the absence of a clear and substantial benefit of chemo-immunotherapy in metastatic $B C$, it seems essential to consider new therapeutic combinations by exploring the immune effects of different therapies. This "pick the winner" approach was recently tested in the TONIC trial [45], and showed that not all chemotherapies used in MBC have the same effect on the induction of an immune response amenable to enhancing the efficacy of immunotherapy with nivolumab.

Several important points should thus be taken into account: (i) the immunological effect of the therapies conventionally used in BC (targeted therapies, chemotherapy, kinase inhibitors, etc.) and (ii) the immune tumor microenvironment. The immunological effects of drugs can vary widely, but the tumor itself can also modulate its environment in various ways, in quantitative, qualitative and topographical terms, to make it hostile to the immune response. This leads to the appearance of different tumor subgroups, namely inflammatory tumors termed "hot" tumors; non-inflammatory or "cold" tumors, and "immune-excluded" tumors. A hot tumor is described as a tumor highly infiltrated by immune cells and frequently associated with high PD-L1 and interferon- $\gamma$ (IFN $\gamma$ ) signature expression (and therefore, a priori, sensitive to anti-tumor immunity). Conversely, a cold tumor is characterized by a paucity, or total lack of immune cell infiltration and anti-tumor immune response [46]. Immune-excluded tumors are tumors where the action of the immune system is limited by the presence of a physical barrier that prevents the immune cells from infiltrating the tumor. There is thus a strong rationale for combining immunotherapy comprising an anti-PD-L1/PD1 checkpoint inhibitor with therapies capable of converting a cold tumor into a hot tumor, enabling increased expression of PD-L1. On the other hand, it also seems possible to combine ICB with some conventional therapies capable of eliminating the physical barrier, thereby activated and efficient immune cells to infiltrate the tumor.

The objective of this review is to take stock of preclinical and clinical data in order to identify, among the therapies used in breast cancer, those most relevant to sensitize: (i) non-immunogenic or non-antigenic cold tumors, (ii) immunosuppressed cold tumors, 
and (iii) immune-excluded tumors. There are currently a large number of clinical trials testing therapeutic combinations with immunotherapy in breast cancer, most of them evaluating combinations incorporating PD-(L)1 inhibitors [47].

\section{Turning a Non-Antigenic and Non-Immunogenic "Cold" BC Tumor into a "Hot" Tumor}

It now well recognized that the quantitative and qualitative composition of the tumor immune micro-environment influences not only the prognosis of the disease but also the effectiveness of certain treatments such as ICI. Patients with apparently the same type of tumor can in fact have immunologically very different immune TME, which is important to know in order to adapt the therapeutic strategy. In a simple way, tumors can be divided into two main categories according to their immune TME. "Hot" tumors are characterized by a strong infiltration of $\mathrm{T}$ lymphocytes, transcriptomic signatures of a favorable inflammatory response (interferon- $\gamma$ ), and frequently a strong expression of PDL1 testifying to this immune response. These tumors have a high probability of responding well to therapeutic approaches based on ICI. Conversely, cold tumors are characterized by low $\mathrm{T}$ lymphocyte infiltration (immune desert) or $\mathrm{T}$ infiltration remaining at the periphery of the tumor (immuno-excluded phenotype), associated with the absence of other signs of an effective inflammatory response $[48,49]$. Several mechanisms can explain the "cold" tumor phenotype associated with resistance to PD-(L)1 blockade. The two main ones are: (i) loss of antigenicity, and/or (ii) loss of immunogenicity.

Poorly antigenic tumor can be explained by a low tumor mutational burden (TMB), which is common in BC [50], and associated with a lower probability of expressing tumorspecific antigens (neoantigens). Tumor cells can also lose their capacity for antigen processing and/or presentation, for example after genetic deletion of MHC-I loci or by JAK1/2 mutation and subsequent inhibition of INF $\gamma$-induced MHC-I expression [51-54]. Reduced expression of MHC I has been observed in human breast cancer samples [55].

The absence of immunogenicity may be due to low release during ICD of DAMPs such as extracellular high mobility group box 1 (HMGB1), adenosine tri phosphate (ATP), calreticulin (CRT), or double-stranded DNA (dsDNA) (Figure 1), and/or the induction of inhibitory pathways, such as toll like receptor 4 (TLR4) signaling inhibition, CD39/CD73, CD47 or Trex expression [56]. Accordingly, tumors with both poor antigenicity and a low level of inflammation are generally much more resistant to immunotherapy [57]. This is the case of the majority of BC, which present both a low TBM and a low level of inflammation, unlike immunogenic NSCLC or melanoma tumors [58]. Therefore, identifying therapies that can upregulate antigenicity and/or immunogenicity in breast tumors is essential to sensitize these tumors to immunotherapy, particularly inhibitors of the PD1/PD-L1 axis. The first part of this review will therefore focus on the effects of existing therapies capable of stimulating these two biological processes.

\subsection{Therapeutic Approaches to Increasing Antigenicity}

\subsubsection{Poly ADP Ribose Polymerase Inhibitors (PARPi)}

PARPi (olaparib, talazoparib) are currently approved for MBC patients with deleterious germinal BRCA1/2 mutations. These tumors with homologous repair deficiency and treated with PARPi are characterized by high genomic instability, and high numbers of DNA breaks, thus generating dsDNA fragments able to activate the interferon pathway (and thus increased MHC expression) in treated cancer cells by stimulating the STING (Stimulator of Interferon Genes) pathway [60,61]. Moreover, it has been postulated that this high genomic instability could also generate non synonymous mutations, translating into potentially immunogenic neoantigens. These BRCA-mutated tumors have been also described as being more infiltrated by immune cells [62].

Additionally, in cancer cell lines, xenograft and syngeneic mouse models of BC, administration of PARPi (olaparib and talazoparib) has been shown to induce PD-L1 expression [63]. In the context of BRCA2-deficient BC, Sato et al. reported that PARPi-induced dsDNA 
breaks could directly regulate PD-L1 through the ATM-ATR-Chk1 pathway, independently of the type I interferon pathway [64]. A further study found that upregulation of PD-L1 was mainly linked to the increase in anti-cancer immune response and relied on activation of the STING/TBK1/IRF3 pathway by cytosolic dsDNA generation after olaparib treatment [65]. Consequently, preclinical studies shown that the combination of PD-L1 blockade plus PARPi is additive against tumor growth in different TNBC and ovarian models $[60,63]$. Based on the encouraging results of these preclinical studies, a series of clinical trials are underway to assess the efficacy of PARPi in combination with ICI in a wide range of cancers, including BC.

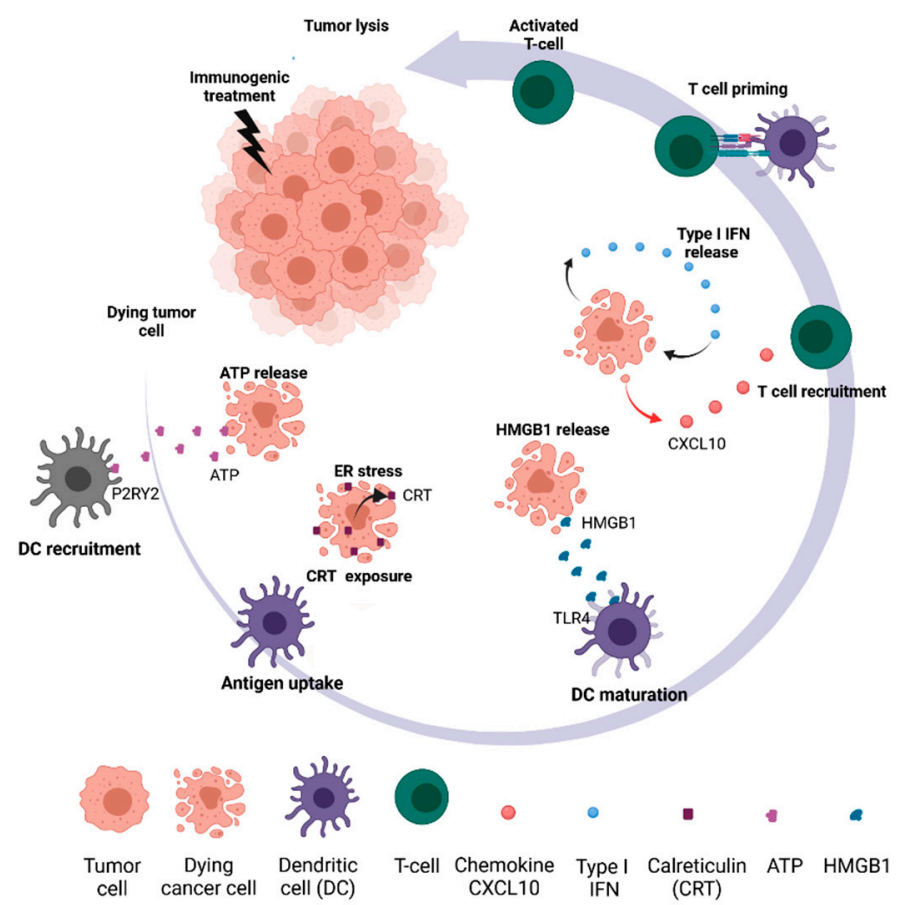

Figure 1. Molecular basis of immunogenic cancer cell death (ICD) (Inspired by Galluzzi et al. 2016 [59] and created with BioRender.com).

The association of durvalumab (an anti PD-L1) with olaparib in patients with germline BRCA1/2 metastatic ER+ or TNBC yielded a disease control rate of $80 \%$ at 12 weeks (primary efficacy endpoint), with a median duration of response of 9.2 months in the phase I/II MEDIOLA [66].

The phase II Keynote-162/TOPACIO study evaluated the effect of a combination of niraparib and pembrolizumab in mTNBC [67] (NCT02657889). This combination appeared to be safe and provided an interesting antitumor effect ( $29 \%$ overall response rate), particularly in patients with germline BRCA mutation (67\% overall response rate) [67]. Moreover, PD-L1-positive tumors responded better than PD-L1 negative (33\% vs. $15 \%$ ).

\subsubsection{MEK Inhibitors}

Multiple signaling pathways involved in oncogenesis can be activated in parallel to the PD-L1 pathway during tumor immune escape. For example, the MAPkinase pathway is involved in the fight against inflammation by inhibiting the secretion of pro-inflammatory cytokines such as IFN $\gamma$ [68]. An interesting opportunity for therapeutic synergy is, therefore, to target oncogenic pathways when these also participate in immune escape. Accordingly, inhibition of the MAP kinase pathway (frequently activated in many solid tumors including $\mathrm{BC}$ ) using a MEK inhibitor seems capable of increasing expression of MHC I and II, PD-L1 expression, tumor infiltration by $\mathrm{CD} 8^{+} \mathrm{T}$ cells, thereby sensitizing tumors to anti-PD-1 immunotherapy $[69,70]$.

It was recently observed that a combination of anti-PD-(L) 1 and a MEK inhibitor (trametinib) yielded an increase in MHC class I and II expression, and of PD-L1 in vitro 
in human and murine mammary cancer cells, as well as in vivo in mice [71]. In addition, one study showed that, by adding trametinib to anti-PD1 treatment in mice, a significant reduction in tumor volume was observed [70].

Conversely, the recent phase II COLET study combining paclitaxel, atezolizumab and cobimetinib (a MEK inhibitor) did not show any additional efficacy compared to treatment with paclitaxel and atezolizumab only [72]. A possible explanation for these disappointing results is that MEK inhibition could be detrimental to the functionality and activation of T lymphocytes [73]. These preclinical data illustrate the difficulty of targeting a cellular pathway that may have opposing roles in immune and tumor cells. Other BC studies are under way with various MEK inhibitors such as selumetinib, which showed an acceptable toxicity profile in combination with an mTORC1/2 inhibitor (vistusertib) in a phase $\mathrm{Ib} / \mathrm{II}$ a trial, with lasting stability in $\mathrm{mTNBC}$ patients [74]. A phase I/II clinical trial of pembrolizumab plus binimetinib is currently ongoing in the setting of local and metastatic triple negative breast cancer (NCT03106415).

\subsubsection{CDK4/6 Inhibitors}

CDK4/ 6 inhibitors such as palbociclib, ribociclib, and abemaciclib have led to improved progression-free and overall survival in $\mathrm{HR}+$ patients [75]. Some studies show that treatment with CDK4/ 6 inhibitors increases MHC class I expression by BC cells. CDK4/6 inhibitors work primarily by suppressing the phosphorylation of retinoblastoma protein $(\mathrm{Rb})$ in cancer cells, which stops the cell cycle and inhibits proliferation. Besides these anti-proliferative effects, it has been shown that CDK4/ 6 inhibitors can increase antigen presentation by MHC class I molecules in models of BC lines, and increase expression of MHC class I and II molecules, partly through re-expression of endogenous retroviral sequences. CDK4/ 6 inhibitors are also able to induce cell-cycle arrest and tumor cell senescence, thus leading to the activation of the SASP (senescence-associated secretory phenotype); which in turn can induce recruitment of immune cells into the tumor microenvironment [76-78].

In these mouse models, CDK4/6 inhibitors synergized with immunotherapy, or immunogenic chemotherapy and increased survival in treated animals. The first phase I/II clinical study to show favorable results tested abemaciclib and pembrolizumab in patients with $\mathrm{HR}+$ metastatic BC, and reported four patients (14\%) with objective response at 24 weeks [79]. Similar studies are under way in other types of cancer.

\subsubsection{Combinations with Other Immunotherapies}

Targeting the PD-1/PDL1 axis as the sole immunotherapy approach is arguably insufficient to reinvigorate the anti-tumor immune response in many patients.

Complementary immunotherapy approaches to anti-PD-1/PD-L1 must therefore be devised in order to increase the presentation of tumor antigens, increase tumor infiltration into immune cells, and/or increase the activity of cellular effectors.

These alternative immunotherapy approaches make use of anti-tumor vaccines, cytokines, or molecules targeting other activating or inhibiting checkpoints of the immune response. The rationale for their combination with anti-PD-1/PD-L1 has been the subject of many recent reviews, e.g., [80].

To date, relatively few combined immunotherapy approaches have been reported in BC. However, many studies have been launched (with T-cell targeted immunomodulators, other immunomodulators, cancer vaccines, oncolytic viruses, or T-cell targeted bispecific $\mathrm{mAb}$ ) [47]. Antibodies targeting LAG3 are one example of the type of immunotherapy aimed at increasing antigenicity: LAG3 is a surface molecule that binds to MHC class II on antigen presenting cells, thereby preventing $\mathrm{T}$ cells from binding to MHC class II, thus preventing their activation. A number of antibodies targeting LAG3 are under development, as well as bispecific antibodies that engage both LAG-3 and PD-1/L1 (NCT03219268, NCT03440437) (Table 1). 
Table 1. Immunotherapy combinations in clinical trial including anti-PD-(L)1 antibody.

\begin{tabular}{|c|c|c|c|}
\hline Trial Name/Number & Phase & Subtype/Condition & Immunotherapy Combinations \\
\hline NCT03219268 & I & $\begin{array}{l}\text { HER2/TNBC Advanced } \\
\text { Solid Tumors }\end{array}$ & MGD013:Bispecific antibodies anti-LAG3/anti-PD-1 \\
\hline NCT03440437 & $\mathrm{I} / \mathrm{II}$ & $\begin{array}{l}\text { Advanced Cancer } \\
\text { Metastatic Cancer }\end{array}$ & FS118: Bispecific antibodies anti-LAG3/anti-PD-L1 \\
\hline DUET-2 NCT03517488 & I & Advanced Solid Tumors & $\begin{array}{c}\text { XmAb®20717: Bispecific antibodies } \\
\text { anti-CTLA4/anti-PD-1 }\end{array}$ \\
\hline NCT01968109 & $\mathrm{I} / 2 \mathrm{a}$ & Advanced Solid Tumors & $\begin{array}{c}\text { Nivolumab (anti-PD-1 antibody) + BMS-936558 } \\
\text { (anti-LAG3 antibody) }\end{array}$ \\
\hline $\begin{array}{l}\text { AIPAC-002 } \\
\text { NCT04252768 }\end{array}$ & I & Metastatic Breast Cancer HR+ & Eftilagimod Alpha (Soluble LAG-3 Protein) + paclitaxel \\
\hline \multirow{3}{*}{ InCITe NCT03971409 } & \multirow{3}{*}{ II } & \multirow{3}{*}{ Stage IV or Unresectable TNBC } & $\begin{array}{l}\text { PF-04518600 (Anti-OX40 antibody) + Avelumab } \\
\text { (anti-PD-L1 antibody) }\end{array}$ \\
\hline & & & 4-1BB/CD137 agonist+ avelumab \\
\hline & & & Sacituzumab govitecan (anti-Trop2 antibody) + avelumab \\
\hline NCT02794571 & $\mathrm{Ia} / \mathrm{Ib}$ & Advanced/Metastatic Tumors & $\begin{array}{l}\text { Tiragolumab (anti-TIGIT antibody) + Atezolizumab } \\
\text { (anti-PD-L1 antibody) + chemotherapies }\end{array}$ \\
\hline NCT04584112 & $\mathrm{Ib}$ & TNBC & Tiragolumab + Atezolizumab + chemotherapies \\
\hline NCT03742349 & I & TNBC & $\begin{array}{c}\text { Spartalizumab (anti-PD-1 antibody) + } \\
\text { LAG525(anti-LAG-3 antibody) + NIR178 or capmatinib or } \\
\text { MCS110 or canakinumab (anti IL-1 } \beta \text { antibody) }\end{array}$ \\
\hline
\end{tabular}

In addition, antibodies targeting PD-(L)1 checkpoint inhibitors can also be combined with an antibody targeting the CTLA-4 molecule. The CTLA-4 receptor functions as an immune checkpoint to moderate the immune response. It acts as a switch that will inhibit the action of the lymphocyte when it comes into contact with CD80 or CD86 proteins on the surface of an antigen presenting cell [81]. Thus, an anti-CTLA-4 strategy unblocks the antigenic priming phase.

Dual co-inhibition of anti-CTLA-4 and anti-PD-1/L1 has shown improved PFS and OS in melanoma, and there is preclinical data to support its use in BC [82]. A pilot trial of durvalumab (an anti-PD-L1) and tremelimumab (an anti-CTLA-4) in metastatic BC observed an ORR of $17 \%$ in ER+ patients, but an ORR of $43 \%$ in patients TNBC, suggesting that patients with TNBC may be better candidates for this type of treatment [83]. Nevertheless, the toxicity of this double inhibition remains a concern, as a recent analysis of trials in melanoma/renal carcinoma showed increased efficacy but a near doubling of grade 3-4 toxicity compared to Ipilimumab as monotherapy. Dual bispecific immunomodulators combining two inhibitory functions are under study [84]. A phase I trial on the XmAb20717 molecule, a combined PD-1 and CTLA-4 antibody in certain advanced solid tumors is underway (NCT03517488).

The discovery of ICIs involved in T lymphocyte depletion such as LAG-3 or TIGIT has also enabled the development of treatments targeting these molecules, some of which are being tested in advanced BC, in particular TNBC (NCT03742349, NCT01968109, NCT04252768, NCT03971409, NCT02794571, NCT04584112).

2.1.5. Targeting Tumor Antigenicity with Immunological Synergy: The Paradigm of HER-2 Directed Monoclonal Antibodies

The HER 2 oncogene is amplified in about $15 \%$ of $\mathrm{BCs}$, and this tumor associated antigen (TAA) constitutes a target for HER-2 directed monoclonal antibodies (mAbs). These mAbs, e.g., trastuzumab, constitute a pivotal axis of treatment for this BC subtype. In the past few years, it has become clear that part of the antitumor activity of trastuzumab is in fact mediated by the immune system, especially by antibody-dependent cellular 
cytotoxicity (ADCC). Several studies have shown that induction of ADCC is associated with an increase in TILs within the tumors of patients treated with trastuzumab $[9,85,86]$. Similar observations have been made in preclinical mouse models, and in patients with other HER2targeting mAbs, such as pertuzumab and T-DM1 (an antibody-drug conjugate) $[87,88]$. In preclinical models of $B C$, these treatments synergize with diverse immunotherapies, including anti PD-(L)1 [89].

Clinical responses have been observed with the association of trastuzumab and pembrolizumab in patients harboring trastuzumab-resistant tumors [90]. The combination of T-DM1 + atezolizumab also seems feasible, without additional toxicity, but did not show any benefit compared to T-DM1 alone in the KATE-2 study, except in patients with a PD-L1 positive tumor, in whom there was a slight benefit in PFS [91].

These clinical results are ultimately quite disappointing, but trials are still recruiting patients at earlier stages of the disease, especially in the first line of metastatic setting (NCT03199885).

\subsection{Therapeutic Approaches to Increasing Immunogenicity}

After seeing the impact of different therapeutics on the antigenicity of tumor cells, a second step may be involved in the success of combination treatments containing immunotherapy, namely tumor cell immunogenicity. This concept has been demonstrated in mouse models of colorectal cancer treated with anthracyclines [92]. After treatment, and in addition to the purely cytotoxic effect, dying tumor cells may emit danger signals, characterized in particular by the extracellular release of HMGB1 or ATP, membrane calreticulin (CRT) exposure, or secretion of type I interferons and chemoattracting chemokines (CXCL10) (Figure 1). These "danger" signals are intended to alert and mobilize the immune system to recognize antigens and eliminate tumor cells. The association of an immunogenic therapy with immunotherapy therefore makes sense, by enabling the recruitment and activation of immune cells within the tumor [26].

\subsubsection{Chemotherapies}

Among the chemotherapies currently used in $\mathrm{BC}$, anthracyclines, notably doxorubicin, epirubicin or mitoxantrone, are molecules known to induce ICD in different tumor models [92,93]. ICD is considered as a stress response associated with the release of diverse DAMPs (CRT, HMGB1, ATP etc., Figure 1) in addition to enhanced antigen presentation [26,27]. Among the DAMPs, HMGB1 release and CRT re-localization has been established in $\mathrm{BC}$ following exposure of human tumor cells in vitro, but also in vivo in patients treated with doxorubicin or paclitaxel [94]. Moreover, the efficacy of anthracyclinebased adjuvant chemotherapy has been shown to be associated with the integrity of the HMGB1/TLR4 axis [95,96]. In a trastuzumab-resistant HER2+ breast cancer model, an antiHER2 conjugate carrying an anthracycline derivative was shown to induce ICD. Further, combining this with an anti-PD-1 antibody improved tumor regression after treatment [97]. The combination of NKT cell activation with chemotherapy, e.g., gemcitabine or cyclophosphamide (currently used in $\mathrm{BC}$ treatment), enhanced the immunogenicity of breast tumor cells by increasing ICD signals (CRT, ATP, HMGB1) in metastatic breast cancer [98].

A fourth hallmark of ICD has recently been discovered, linked to autocrine signaling of type I interferons (INF-I). The release of nucleic acids by anthracycline-killed tumor cells is detected by TLR3 on persistent viable cells, and acts as a transcription signal for type 1 interferon genes. IFN-I in turn acts on their IFN-I receptors in an autocrine manner, leading to an autocrine IFN-I signature that comprises essential chemotactic factors for the recruitment of immune effectors, like CXCL10 [99].

Expression of chemoattracting chemokines seems crucial for the efficacy of ICIs [100], and it is therefore important to know that certain chemotherapies, such as anthracyclines, are likely to induce their expression. 
However, although chemotherapy and anti-PD1 synergy has been shown in many preclinical models, few clinical trials have compared different chemotherapy regimens in association with the same immunotherapy.

In the phase III Keynote 355 trial, the addition of pembrolizumab to chemotherapy as the first treatment for patients with $\mathrm{mTNBC}$ showed an improvement in PFS regardless of the associated chemotherapy (gemcitabine + carboplatin or different taxanes), but there was no arm with anthracyclines [32]. Conversely, at advanced stages of the disease, doxorubicin and cisplatin were shown to be more likely to give synergic responses in combination with nivolumab in the phase II TONIC trial [45].

Interestingly, the only negative trial (no improvement in $\mathrm{pCR}$ with immunotherapy) combining chemotherapy + immunotherapy in the neoadjuvant treatment of TNBC, is the one in which neoadjuvant chemotherapy did not include anthracyclines [39].

There is therefore a growing body of indirect evidence suggesting that chemotherapeutic agents capable of inducing ICD can synergize more effectively with anti PD-(L)1.

\subsubsection{Radiotherapy}

Radiation therapy is another type of treatment used in BC. In addition to inducing lethal DNA damage in tumor cells, it appears to have an effect on tumor immunity. Indeed, the exposure of tumor cells in vitro and in vivo to different doses of radiation appears to lead to an increase in ICD signals and antigen processing machinery $[23,100]$. Radiotherapy is able to induce ICD of tumor cells, in connection with danger signals emitted as a result of DNA damage caused by radiation [101]. This could explain the abscopal effect of radiotherapy, observed in certain patients [102]. Moreover, in preclinical models of TNBC, Dovedi et al. showed that low dose fractionated radiotherapy could upregulate PD-L1 ligand expression by tumor cells [103]. The combination of radiotherapy and anti-PD-(L)1 immunotherapy produced effective anti-tumor immunity and long-term control of the tumor. BC is a disease that is usually radiosensitive, and radiotherapy is part of the standard treatment for localized breast cancer. Therefore, the association of radiotherapy with immunotherapy could be synergic in $\mathrm{BC}$, as has been shown in lung cancer, for example, in the PACIFIC phase III trial [104]. Many association studies including radiotherapy are currently under way, and have recently been reviewed [105]. In BC, the recently published results of a phase II trial show an encouraging response rate (17.6\%) in heavily pretreated patients when pembrolizumab is added to palliative irradiation of a metastatic site [106,107].

Importantly, it should be noted that the optimal radiation therapy treatment plan (dose and fractionation) to obtain optimal immunological synergy is currently unknown.

Depending on the scheme used, radiotherapy may also have immunosuppressive effects [108], part of which can be counteracted by anti-PD-1 drugs [102,103,109]. The timing of the radiation therapy in relation to the administration of immunotherapy (concurrent or sequential), and the administration schedule of the radiotherapy are possibly at the origin of variable immunological consequences $[23,103,108,109]$ and must be taken into account in the therapeutic combinations. Research is currently ongoing to try to answer these new questions, and to investigate the integration of stereotactic radiotherapy into combination strategies with immunotherapy [110].

\subsubsection{STING Agonists}

STING agonists have emerged as good candidates to promote the recruitment of immune cells in the tumor microenvironment. Indeed, the activation of this pathway leads to the production of type I interferons and an adaptive immune response [111]. Injection of cGAS-NP, a liposomal STING inducer, in preclinical BC models resistant to anti-PDL1 immunotherapy showed a strong increase in IFN $\beta$ expression and secretion, as well as STING/interferon $\alpha / \beta$ receptor (IFNAR)-pathway-dependent tumor regression [112]. The generation of an adaptive immune response was demonstrated by the rejection observed following re-challenge of tumor cells from different mouse models, such as the 
4T1 TNBC, proving that administration of STING agonists provided long-lasting immune memory [113]. The combination with anti-PDL1 immunotherapy is promising because, as proven in melanoma, cGAMP would activate and recruit $\mathrm{CD}^{+} \mathrm{T}$ cells in the microenvironment, and cGAS seems essential for the success of PD-L1 treatment [114]. Interestingly, there seems to be immunological synergy between these treatments, and others capable of strongly inducing breaks in DNA, such as PARPi (especially in BRCA-associated BC) [115].

Currently, there are few available human clinical data in BC and no clinical trials are currently open.

\section{Targeting the Immunosuppressive Microenvironment}

In addition to cancer cells, tumors contain a repertoire of recruited immune and nonimmune cells that contribute to the creation of the "tumor microenvironment". Among these populations, certain cell types have immunosuppressive action, such as macrophages associated with type 2 tumors (TAM2), regulatory T lymphocytes (Treg), tumor associated neutrophils (TAN), Myeloid-Derived Suppressor Cells (MDSC), or cancer associated fibroblasts (CAF). Certain therapies are capable of inhibiting or depleting these immunosuppressive populations, but also of inhibiting the cytokines produced by these immunosuppressive cells. Targeting these cell populations could help to reduce immunosuppression within the tumor, which would in turn sensitize the tumor to immunotherapy via checkpoint inhibitors.

\subsection{Chemotherapies}

Besides the possible induction of ICD, some chemotherapies are known for their depleting effects on immunosuppressive populations, such as cyclophosphamide for Treg lymphocytes [116] or gemcitabine or 5-fluorouracil for MDSC [117]. A preclinical evaluation of a combination of anti-PD-L1 and cyclophosphamide in a mouse model of BC failed to demonstrate a superior effect over cyclophosphamide monotherapy [118]. In contrast, the phase II CHEMOIMMUNE trial of pembrolizumab following treatment with metronomic cyclophosphamide is currently underway in lympho-penic patients with metastatic BC (NCT03139851). Other chemotherapies are able to modify the phenotype of immunosuppressive cells. Indeed, paclitaxel enables repolarization of M2 type macrophages into the M1 antitumor phenotype in a TLR4-dependent manner; this has been shown both in vitro and in vivo in preclinical studies in a 4T1 BC model [119]. In addition, another study revealed that paclitaxel at ultra-low concentrations enables the differentiation of MDSCs into dendritic cells in vitro in a TLR4-independent manner [120].

\subsection{IDO Inhibitors}

Indoleamine 2,3-dioxygenase (IDO) is an enzyme that converts tryptophan to kynurenine, exerting an immunosuppressive effect within the tumor microenvironment. Indeed, kynurenine is an enzyme capable of inactivating effector $\mathrm{T}$ lymphocytes and promoting regulatory T lymphocytes [121]. Like PD-L1, IDO is upregulated by T cells secreting IFN $\gamma$ in the microenvironment as a means of immune escape, and both of these pathways are potentially redundant pathways of immune suppression in BC that present TILs. The combination of indoximod, an orally administered IDO inhibitor, and docetaxel has been tested in solid tumors including BC. The results showed evidence of clinical activity: two partial responses and two minor responses in BC were observed [122] (NCT01792050). Several clinical trials are evaluating the activity of indoximod in combination with anti-PD1 in multiple types of tumors, including BC. Epacadostat is another inhibitor of IDO that recently showed a response rate of $10 \%$ in combination with pembrolizumab in mTNBC [123].

\subsection{The CD39/CD73/Adenosine Pathway}

In BC, adenosine, produced by the CD39 and CD73 ectonucleotidases, mediates numerous molecular pathways of immunosuppression, especially inhibition of $\mathrm{T}$ cell 
proliferation, cytotoxicity, or cytokine production [124,125]. Ectonucleotidase CD73 is particularly expressed in TNBC, and is associated with chemo-resistance [126].

In a preclinical model of TNBC, inhibition of adenosine receptors synergizes with anti-PD-1 in a CD8 ${ }^{+} \mathrm{T}$ cell/NK cell/ and interferon-dependent manner [127]. Oleclumab, an inhibitor of CD73, is currently under clinical evaluation in combination with paclitaxel + carboplatin + durvalumab (anti PD-L1) in the phase I/II SYNERGY in mTNBC patients (NCT03616886).

\subsection{PI3K/AKT Inhibition}

The PI3K/mTOR/AKT pathway is one of the most frequently mutated pathways in $\mathrm{BC}$, prompting the development of various pharmacological inhibitors (PI3 kinase, AKT or mTOR) for BC treatment. Moreover, this pathway also participates in the development of an immunosuppressive environment by increasing the expression of immunosuppressive cytokines and chemokines. This occurs via the recruitment of MDSCs and regulatory $\mathrm{T}$ lymphocytes within the tumor, and through an increase in PD-L1 ligand expression by tumor cells $[128,129]$. Inhibitors targeting this pathway have been developed in recent years such as ipatasertib (an AKT inhibitor), whose first results show a decrease in the number of regulatory $\mathrm{T}$ lymphocytes within the tumor accompanied by an increase in differentiation of $\mathrm{CD}^{+}$lymphocytes into $\mathrm{CD} 8^{+}$memory [130]. In addition, it has been shown that PI3K inhibitors enabled polarization of M2 macrophages from an immunosuppressive phenotype into M1-type macrophages of the antitumor phenotype. Inhibition of PI3K $\gamma$ appears to sensitize tumors to anti-PD-1 antibody therapy and to slow tumor growth by increasing the level of $\mathrm{CD}^{+}$and $\mathrm{CD} 8^{+} \mathrm{T}$ lymphocytes within the tumor [131]. These encouraging preclinical results have prompted the development of these associations in the clinic. Indeed, a study testing ipatasertib in combination with atezolizumab and paclitaxel in patients with localized or metastatic TNBC is currently underway (NCT04177108). Another phase II clinical study combining a PI3K- $\gamma$ inhibitor, IPI-549 (because of the important role of this PI3K isoform in the functions of immunosuppressive myeloid cells), with atezolizumab and nab-paclitaxel is ongoing (NCT03961698).

\subsection{HDAC Inhibitors}

A number of pharmacological agents capable of modifying epigenetics, such as HDAC inhibitors, are currently being investigated in BC.

Besides their direct effect on tumor cells (apoptosis, cell differentiation, growth inhibition), there is great interest in the potential of epigenetic therapy to prime the response to immunotherapy in BC. Studies have shown that epigenetic modulation can promote an IFN type I response and restore production of Th1-type cytokines and chemokines [132,133]. Another preclinical study showed that treating mice bearing solid tumors (including tumors generated with the 4T1 mouse model) with the HDAC inhibitor entinostat, combined with CTLA- 4 and PD- 1 antibodies, could eradicate both primary tumors and metastases by reducing granulocytic MDSCs [134]. HDAC inhibitors are thus able to reduce the immunosuppressive activity of Tregs and MDSCs [134,135].

A phase II clinical trial showed that adding entinostat to exemestane in patients with advanced ER+ BC resulted in an 8.3-month improvement in OS compared to patients treated with exemestane alone [136]. Exploratory studies on blood samples from 34 patients showed a lower number of MDSCs, a decrease in CD40 expression of MDSCs, and an increase in MHC class II expression on $\mathrm{CD}_{14}{ }^{+}$monocytes two weeks after treatment initiation. No alteration of T cell phenotypes was observed. Multiple clinical trials are under way evaluating the combination of epigenetic modulation with PD-(L)1 blockade, or combined blockade of CTLA-4 and PD-1 [137].

\subsection{CDK4/6 Inhibitors}

Beside their effects on tumor antigenicity, CDK4/ 6 inhibitors increase the function of effector $\mathrm{T}$ lymphocytes while markedly suppressing the proliferation of regulatory $\mathrm{T}$ 
lymphocytes [138]. Preclinical and clinical studies have confirmed the increased tumor infiltration by T cells [139] and the decrease in Tregs in treated tumors [140].

\subsection{Autophagy Inhibition}

Certain immunosuppressive populations and their impact on the tumor microenvironment, such as angiogenesis or hypoxia, can promote cancer stem cell (CSCs) resistance [141]. Conversely, CSCs can also interact with these immunosuppressive populations to activate and stimulate them, such as inducing the recruitment and polarization of TAM2 [142]. CSCs are known to be involved in the metastatic capacity of cancers, particularly in breast cancer [143]. Indeed, through their capacity for self-renewal, differentiation and proliferation, these cells will promote the aggressiveness of cancerous lesions. One strategy to target CSCs is the inhibition of autophagy. Indeed, autophagy appears to promote the maintenance and resistance of CSCs in tumors to anti-cancer therapies [144,145]. Targeting this catabolic process could therefore become an interesting approach to limit resistant CSCs. Numerous phase I/II clinical trials evaluating the efficacy of autophagy inhibitors such as chloroquine or hydroxychloroquine are currently being investigated in the treatment of breast cancer [146]. Autophagy inhibition has also shown a positive impact on inflammation and recruitment of cytotoxic populations and appears to improve the efficacy of immunotherapy and justify its combination $[147,148]$.

\section{Counteract Immune-Excluded Tumors}

\subsection{Fibrosis}

Some tumors manage to escape the immune system thanks to the formation of a barrier around their perimeter that prevents the arrival of immune cells within the tumor bed. The formation of this barrier can be explained by the marked fibroblast activation by tumor cells and other immunosuppressive cells, via the influence of TGF- $\beta 1$. Cancer-associated fibroblasts (CAF) and tumor cells produce collagen and matrix proteins that participate in the formation of a fibrous capsule, also called peritumoral fibrosis. Interestingly, in TNBC, specific tumor microenvironment profiles (including a margin-restricted profile of CD8 infiltration) are linked to different transcriptomic subtypes of TNBC [149]. A margin-restricted profile of immune cells is more frequently observed in the mesenchymal stem-like TNBC subtype. This fibrotic barrier consisting of dense tissue enables the tumor to evade the immune system [150]. Furthermore, TGF- $\beta 1$ produced within the tumor microenvironment has a central role in immunosuppression, as this cytokine can alter the efficacy of anti-tumor populations and promote pro-tumor populations [151]. Targeting this molecule could therefore make it possible to sensitize BCs to other immunotherapeutic approaches, including anti PD-(L)1. Several methods are currently available to target TGF- $\beta 1$, such as monoclonal antibodies or TGF- $\beta 1$ receptor inhibitors. Tauriello et al. have shown that in mouse models of colon and liver cancer, treatment with galunisertib, a TGF$\beta 1$ receptor II inhibitor, resulted in an increase in T-CD8 ${ }^{+}$cell activation, associated with a decrease in the number of metastases. In contrast, there appears to be no improvement in survival when targeting TGF- $\beta 1$ alone [152]. In addition, immune system involvement, specifically $\mathrm{CD} 8^{+} \mathrm{T}$ cells, was found to be involved in the response to galunisertib treatment in a 4T1 mouse model of BC [153]. Bhola et al. combined galunisertib with paclitaxel treatment in mice, and observed a decrease in tumor volume with inactivation of the SMAD pathway, compared to paclitaxel treatment alone [154]. In BC, a combination of galunisertib and paclitaxel is currently being tested in patients with TNBC (NCT02672475).

Targeting TGF- $\beta 1$ is also possible with the use of monoclonal antibodies. Preclinical use of dual immunotherapy comprising an anti-TGF- $\beta 1$ and an anti-PD-L1 significantly increases mouse survival [155]. The authors proposed that TGF- $\beta 1$, by repressing lymphocyte infiltration within the tumor, prevents the action of anti-PD-1 or anti-PD-L1 treatment [155]. In humans, an anti-TGF- $\beta 1$ antibody, fresolimumab is being tested in clinical trials, particularly in combination with radiotherapy in MBC. Results to date showed that patients 
receiving the highest dose of fresolimumab had a favorable systemic immune response and longer median OS than the lowest dose group (NCT01401062) [156].

In parallel, M7824 (bintrafusp alfa), a bifunctional fusion protein targeting TGF- $\beta$ and PD-L1, is currently being tested in phase II and III clinical trials for many types of cancer. Compared to dual immunotherapy, M7824 showed greater anti-tumor efficacy in the EMT6 preclinical model [157]. Clinical studies are evaluating the efficacy of M7824 in HER2+ breast cancer (NCT03620201) and in TNBC (NCT04489940). In addition, the combination of this bispecific antibody with other therapies such as chemotherapy and radiotherapy is also being investigated. The effects of the combination of M7824 and chemotherapy with eribulin are currently being studied in TNBC (NCT03579472M). Lastly, the combination of radiotherapy and the M7824 antibody is currently being investigated in metastatic ER+/HER2- BC patients (NCT03524170).

\subsection{Tumor Angiogenesis}

Angiogenesis is the process of creating new vessels. During tumor growth, angiogenesis is necessary to reduce hypoxia and increase nourishment for tumor cell development [158]. Vascular endothelial growth factor (VEGF) and fibroblast growth factor (FGF) are two angiogenic growth factors involved in tumor progression [159]. In addition to reducing the density of neo tumor vessels, leading to hypoxia in cancer cells, anti-angiogenic therapies could help to normalize the tumor vasculature, thus facilitating immune cell trafficking in the tumor [160]. Moreover, certain agents targeting VEGF or its receptors have also shown that they could selectively deplete certain populations of immunoregulatory cells, as well as increase tumor expression of PD-L1 [161].

Pre-clinical data suggest that targeting the proangiogenic cytokines Vascular endothelial growth factor A (VEGF-A) and angiopoietin-2 (Ang-2) by a bispecific blocking antibody in an inducible model of BC leads to an increase in PD-L1 expression on epithelial cells in response to the induction of IFN $\gamma$ and cytotoxic T lymphocytes. In this setting, combining this approach with anti-PD-L1 immunotherapy yields a prolongation of survival in $30 \%$ of mice compared to monotherapy [162].

The MORPHEUS phase $1 \mathrm{~b} / \mathrm{II}$ clinical trial is currently recruiting patients HR+HER2or TNBC to evaluate the efficacy and toxicity of combining treatments with immunotherapy, such as atezolizumab + bevacizumab + endocrine therapy or atezolizumab + bevacizumab + anti-CD40 (NCT03280563) (NCT03424005). The ECLIPSE II clinical trial is evaluating the effects of combination immunotherapy in $\mathrm{ER}^{+} \mathrm{HER}^{-}$patients. Atezolizumab is combined with anti-MEK, anti-PI3K or bevacizumab+anti-MEK (NCT03395899). Another phase II clinical trial was conducted in women with TNBC treated by an anti-PD1 in combination with a VEGFR2 inhibitor. This combination seems to be effective, and to display strong synergy, with an ORR of $43.3 \%$ vs. $<20 \%$ for monotherapies (NCT03394287) [163].

New anti-angiogenic compounds like famitinib are also in development in association with a new anti-PD-1, camrelizumab, in mTNBC with nab-paclitaxel as the chemotherapy backbone (NCT04129996).

\section{Other Approaches}

Innovative new approaches to immunotherapy are being developed with the aim of "heating up" cold or immune-excluded tumors. Among the options being investigated is intra-tumor administration of talimogene laherparepvec (T-VEC), an oncolytic herpes simplex 1 virus approved for the treatment of melanoma. A phase 1 trial of T-VEC in combination with neoadjuvant chemotherapy for the treatment of non-metastatic TNBC recently reported that this combination was feasible and led to a complete response rate of 55\% [122]. Other trials associating T-VEC with ICI are ongoing, for example TVEC + atezolizumab in residual disease after standard neoadjuvant chemotherapy (NCT03802604).

Adoptive cell therapy using CAR-T cells or TILs in association with anti PD-(L)1 ICI are starting to be developed in $\mathrm{BC}$, and some case reports have shown that this strategy can give strong and lasting tumor responses in very selected patients [164]. In mTNBC, 
numerous phase 1 trials are currently ongoing with CAR-T cells directed against various tumor antigens (mesothelin, cMET, MUC1, ... ) [165].

It should be noted that many new effective cytotoxic treatments are currently being developed in $\mathrm{BC}$ in the form of antibiotic-drug conjugates (ADC): even in the absence of a strong immunological rationale, several combination trials are already testing anti-PD-1 with sacituzumab govitecan (an antibody targeting the human trophoblast cell-surface antigen 2) (NCT03424005, NCT04468061), or ladiratuzumab vedotin [166].

\section{Conclusions}

Clinical results with anti-PD-(L)1 immunotherapy in breast cancer are mixed. It seems that monotherapy with these ICIs is clearly not sufficient to induce a deep and lasting response in the majority of patients, making it necessary to combine them with other treatments to achieve therapeutic synergy (Figure 2).

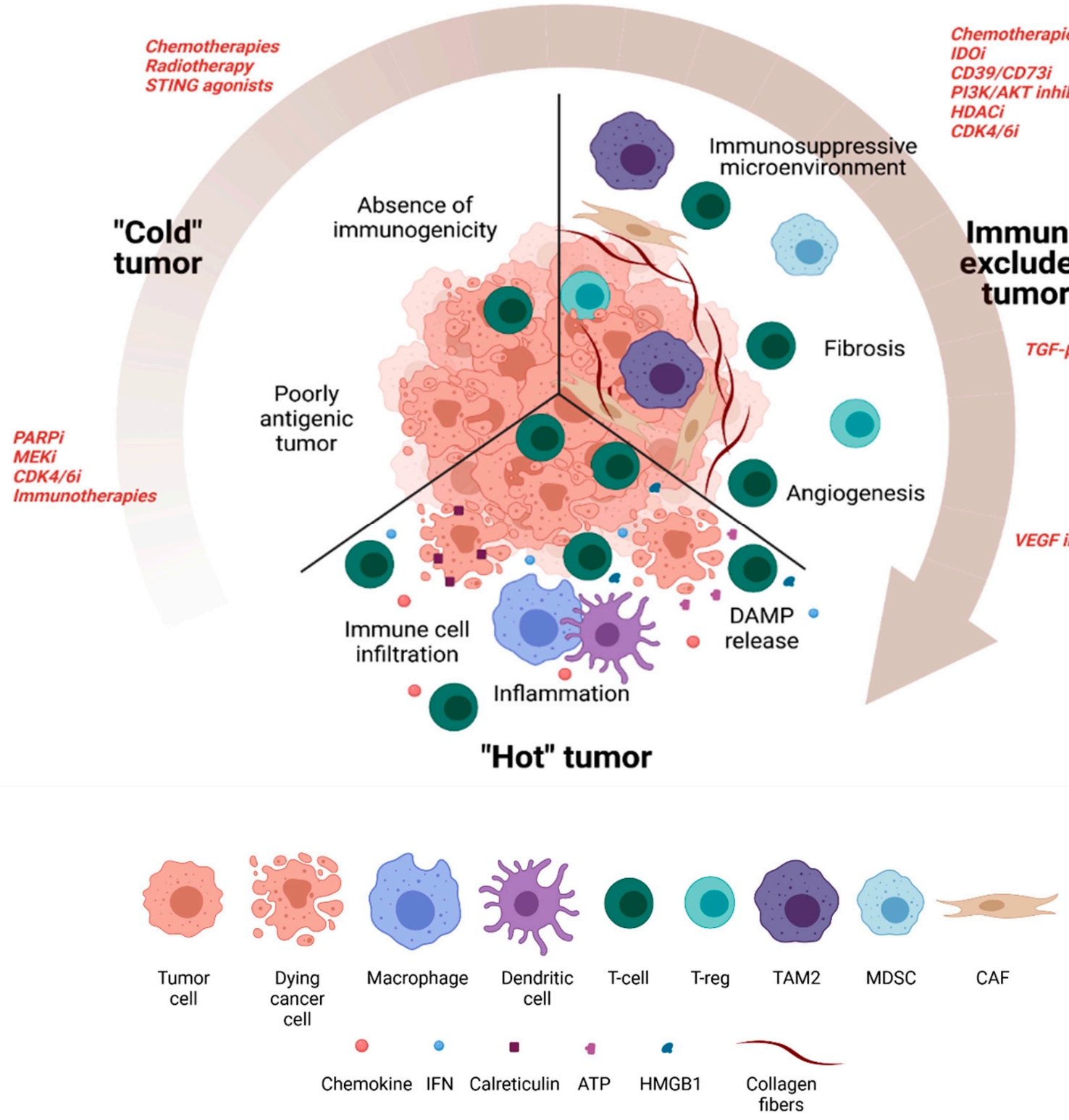

Figure 2. The different tumor immunophenotypes in breast cancer: "cold" tumor, immune-excluded tumor and "hot" tumor (Created with BioRender.com). 
A large number of association trials are currently under way in all BC subtypes, and, in parallel, in metastatic and in early stage disease. However, it is worrying to note that all these efforts are moving forward in an uncoordinated manner, and most often without a strong immunological rationale.

It is quite probable that treatments based on immunotherapy only work in certain subgroups of BC subtypes and/or patients. Consequently, identifying these different clinical-biological entities, and their respective probability of response, should be a priority, in order to select the patients who may most benefit now from existing drugs (to clearly confirm the benefit), and conversely to prioritize access to clinical research programs for others, with a view to increasing the probability of response through therapeutic associations. In addition, the optimal schedule of administration of ICIs targeting PD-1 or PD-L1 with other therapeutic partners, their respective doses, and the treatment sequence are points that remain to be clarified.

The challenges to be faced in the years to come are daunting if immunotherapy is to reach its full potential in breast cancer. We must continue our search to find the best possible combination for a given patient, depending on the subtype of disease, the tumor immune microenvironment, and the patient's immunological context (degree of immunosuppression, microbiota, comedications, etc.).

Author Contributions: Writing review and editing, F.L., L.K. and L.G.; supervision, E.L. and S.L.; funding acquisition, S.L. All authors have read and agreed to the published version of the manuscript.

Funding: F.L., L.K., E.L. and S.L. are supported by the Ligue Nationale contre le Cancer (Equipes labellisées), the Ligue Nationale contre le Cancer Grand-Est, the Institut National du Cancer (INCa), the Association pour la Recherche sur le Cancer (ARC), the Fondation AMGEN, the LabEx LipSTIC, the Région Bourgogne-Franche-Comte (BFC), and the I-Site-BFC program. This study was also supported by the Georges-François Leclerc Cancer Center.

Conflicts of Interest: S.L. received fees for oral communication and travel grants from Lilly, Pfizer, Novartis, Bristol-Myers Squibb, Roche, Ipsen, Janssen Oncology, and Sanofi. Other authors have no potential conflict of interest to disclose. Other authors declare no conflict of interest.

\section{References}

1. Sung, H.; Ferlay, J.; Siegel, R.L.; Laversanne, M.; Soerjomataram, I.; Jemal, A.; Bray, F. Global Cancer Statistics 2020: GLOBOCAN Estimates of Incidence and Mortality Worldwide for 36 Cancers in 185 Countries. CA Cancer J. Clin. 2021, 71, 209-249. [CrossRef]

2. Loibl, S.; Poortmans, P.; Morrow, M.; Denkert, C.; Curigliano, G. Breast Cancer. Lancet 2021, 397, 1750-1769. [CrossRef]

3. Darvin, P.; Toor, S.M.; Sasidharan Nair, V.; Elkord, E. Immune Checkpoint Inhibitors: Recent Progress and Potential Biomarkers. Exp. Mol. Med. 2018, 50, 1-11. [CrossRef] [PubMed]

4. De La Cruz, L.M.; Czerniecki, B.J. Immunotherapy for Breast Cancer Is Finally at the Doorstep: Immunotherapy in Breast Cancer. Ann. Surg Oncol. 2018, 25, 2852-2857. [CrossRef] [PubMed]

5. Solinas, C.; Gombos, A.; Latifyan, S.; Piccart-Gebhart, M.; Kok, M.; Buisseret, L. Targeting Immune Checkpoints in Breast Cancer: An Update of Early Results. ESMO Open 2017, 2, e000255. [CrossRef] [PubMed]

6. Griguolo, G.; Serna, G.; Pascual, T.; Fasani, R.; Guardia, X.; Chic, N.; Paré, L.; Pernas, S.; Muñoz, M.; Oliveira, M.; et al. Immune Microenvironment Characterisation and Dynamics during Anti-HER2-Based Neoadjuvant Treatment in HER2-Positive Breast Cancer. NPJ Precis. Oncol. 2021, 5, 1-12. [CrossRef]

7. Loi, S.; Michiels, S.; Salgado, R.; Sirtaine, N.; Jose, V.; Fumagalli, D.; Kellokumpu-Lehtinen, P.-L.; Bono, P.; Kataja, V.; Desmedt, C.; et al. Tumor Infiltrating Lymphocytes Are Prognostic in Triple Negative Breast Cancer and Predictive for Trastuzumab Benefit in Early Breast Cancer: Results from the FinHER Trial. Ann. Oncol 2014, 25, 1544-1550. [CrossRef]

8. Savas, P.; Salgado, R.; Denkert, C.; Sotiriou, C.; Darcy, P.K.; Smyth, M.J.; Loi, S. Clinical Relevance of Host Immunity in Breast Cancer: From TILs to the Clinic. Nat. Rev Clin. Oncol. 2016, 13, 228-241. [CrossRef] [PubMed]

9. Musolino, A.; Naldi, N.; Bortesi, B.; Pezzuolo, D.; Capelletti, M.; Missale, G.; Laccabue, D.; Zerbini, A.; Camisa, R.; Bisagni, G.; et al. Immunoglobulin G Fragment C Receptor Polymorphisms and Clinical Efficacy of Trastuzumab-Based Therapy in Patients with HER-2/Neu-Positive Metastatic Breast Cancer. J. Clin. Oncol. 2008, 26, 1789-1796. [CrossRef] [PubMed]

10. Denkert, C.; von Minckwitz, G.; Darb-Esfahani, S.; Lederer, B.; Heppner, B.I.; Weber, K.E.; Budczies, J.; Huober, J.; Klauschen, F.; Furlanetto, J.; et al. Tumour-Infiltrating Lymphocytes and Prognosis in Different Subtypes of Breast Cancer: A Pooled Analysis of 3771 Patients Treated with Neoadjuvant Therapy. Lancet Oncol. 2018, 19, 40-50. [CrossRef] 
11. He, L.; Wang, Y.; Wu, Q.; Song, Y.; Ma, X.; Zhang, B.; Wang, H.; Huang, Y. Association between Levels of Tumor-Infiltrating Lymphocytes in Different Subtypes of Primary Breast Tumors and Prognostic Outcomes: A Meta-Analysis. BMC Womens Health 2020, 20, 194. [CrossRef] [PubMed]

12. Ladoire, S.; Martin, F.; Ghiringhelli, F. Prognostic Role of FOXP3+ Regulatory T Cells Infiltrating Human Carcinomas: The Paradox of Colorectal Cancer. Cancer Immunol. Immunother. 2011, 60, 909-918. [CrossRef] [PubMed]

13. Ladoire, S.; Arnould, L.; Apetoh, L.; Coudert, B.; Martin, F.; Chauffert, B.; Fumoleau, P.; Ghiringhelli, F. Pathologic Complete Response to Neoadjuvant Chemotherapy of Breast Carcinoma Is Associated with the Disappearance of Tumor-Infiltrating Foxp3+ Regulatory T Cells. Clin. Cancer Res. 2008, 14, 2413-2420. [CrossRef] [PubMed]

14. Stanton, S.E.; Adams, S.; Disis, M.L. Variation in the Incidence and Magnitude of Tumor-Infiltrating Lymphocytes in Breast Cancer Subtypes: A Systematic Review. JAMA Oncol. 2016, 2, 1354-1360. [CrossRef] [PubMed]

15. Dieci, M.V.; Miglietta, F.; Guarneri, V. Immune Infiltrates in Breast Cancer: Recent Updates and Clinical Implications. Cells 2021, 10, 223. [CrossRef]

16. Nanda, R.; Chow, L.Q.M.; Dees, E.C.; Berger, R.; Gupta, S.; Geva, R.; Pusztai, L.; Pathiraja, K.; Aktan, G.; Cheng, J.D.; et al. Pembrolizumab in Patients With Advanced Triple-Negative Breast Cancer: Phase Ib KEYNOTE-012 Study. J. Clin. Oncol. 2016, 34, 2460-2467. [CrossRef] [PubMed]

17. Emens, L.A.; Cruz, C.; Eder, J.P.; Braiteh, F.; Chung, C.; Tolaney, S.M.; Kuter, I.; Nanda, R.; Cassier, P.A.; Delord, J.-P.; et al. Long-Term Clinical Outcomes and Biomarker Analyses of Atezolizumab Therapy for Patients With Metastatic Triple-Negative Breast Cancer: A Phase 1 Study. JAMA Oncol. 2019, 5, 74-82. [CrossRef]

18. Wang, X.; Yang, X.; Zhang, C.; Wang, Y.; Cheng, T.; Duan, L.; Tong, Z.; Tan, S.; Zhang, H.; Saw, P.E.; et al. Tumor Cell-Intrinsic PD-1 Receptor Is a Tumor Suppressor and Mediates Resistance to PD-1 Blockade Therapy. Proc. Natl. Acad. Sci. USA 2020, 117, 6640-6650. [CrossRef] [PubMed]

19. Schmid, P.; Cruz, C.; Braiteh, F.S.; Eder, J.P.; Tolaney, S.; Kuter, I.; Nanda, R.; Chung, C.; Cassier, P.; Delord, J.-P.; et al. Abstract 2986: Atezolizumab in Metastatic TNBC (MTNBC): Long-Term Clinical Outcomes and Biomarker Analyses. Cancer Res. 2017, $77,2986$.

20. Adams, S.; Schmid, P.; Rugo, H.S.; Winer, E.P.; Loirat, D.; Awada, A.; Cescon, D.W.; Iwata, H.; Campone, M.; Nanda, R.; et al. Pembrolizumab Monotherapy for Previously Treated Metastatic Triple-Negative Breast Cancer: Cohort A of the Phase II KEYNOTE-086 Study. Ann. Oncol. 2019, 30, 397-404. [CrossRef] [PubMed]

21. Cortés, J.; Lipatov, O.; Im, S.-A.; Gonçalves, A.; Lee, K.S.; Schmid, P.; Tamura, K.; Testa, L.; Witzel, I.; Ohtani, S.; et al. LBA21KEYNOTE-119: Phase III Study of Pembrolizumab (Pembro) versus Single-Agent Chemotherapy (Chemo) for Metastatic Triple Negative Breast Cancer (MTNBC). Ann. Oncol. 2019, 30, v859-v860. [CrossRef]

22. Dirix, L.Y.; Takacs, I.; Jerusalem, G.; Nikolinakos, P.; Arkenau, H.-T.; Forero-Torres, A.; Boccia, R.; Lippman, M.E.; Somer, R.; Smakal, M.; et al. Avelumab, an Anti-PD-L1 Antibody, in Patients with Locally Advanced or Metastatic Breast Cancer: A Phase 1b JAVELIN Solid Tumor Study. Breast Cancer Res. Treat. 2018, 167, 671-686. [CrossRef] [PubMed]

23. Gameiro, S.R.; Jammed, M.L.; Wattenberg, M.M.; Tsang, K.Y.; Ferrone, S.; Hodge, J.W. Radiation-Induced Immunogenic Modulation of Tumor Enhances Antigen Processing and Calreticulin Exposure, Resulting in Enhanced T-Cell Killing. Oncotarget 2013, 5, 403-416. [CrossRef] [PubMed]

24. Aymeric, L.; Apetoh, L.; Ghiringhelli, F.; Tesniere, A.; Martins, I.; Kroemer, G.; Smyth, M.J.; Zitvogel, L. Tumor Cell Death and ATP Release Prime Dendritic Cells and Efficient Anticancer Immunity. Cancer Res. 2010, 70, 855-858. [CrossRef]

25. Hernandez, C.; Huebener, P.; Schwabe, R.F. Damage-Associated Molecular Patterns in Cancer: A Double-Edged Sword. Oncogene 2016, 35, 5931-5941. [CrossRef] [PubMed]

26. Kroemer, G.; Galluzzi, L.; Kepp, O.; Zitvogel, L. Immunogenic Cell Death in Cancer Therapy. Annu. Rev. Immunol. 2013, 31, 51-72. [CrossRef] [PubMed]

27. Galluzzi, L.; Buqué, A.; Kepp, O.; Zitvogel, L.; Kroemer, G. Immunological Effects of Conventional Chemotherapy and Targeted Anticancer Agents. Cancer Cell 2015, 28, 690-714. [CrossRef] [PubMed]

28. Adams, S.; Diamond, J.; Hamilton, E.; Pohlmann, P.; Tolaney, S.; Chang, C.-W.; Zhang, W.; Iizuka, K.; Foster, P.; Molinero, L.; et al. Atezolizumab Plus Nab-Paclitaxel in the Treatment of Metastatic Triple-Negative Breast Cancer With 2-Year Survival Follow-up: A Phase 1b Clinical Trial. JAMA Oncol. 2018, 5, 334-342. [CrossRef] [PubMed]

29. Tolaney, S.M.; Barroso-Sousa, R.; Keenan, T.; Li, T.; Trippa, L.; Vaz-Luis, I.; Wulf, G.; Spring, L.; Sinclair, N.F.; Andrews, C.; et al. Effect of Eribulin with or without Pembrolizumab on Progression-Free Survival for Patients With Hormone Receptor-Positive, ERBB2-Negative Metastatic Breast Cancer: A Randomized Clinical Trial. JAMA Oncol. 2020, 6, 1598-1605. [CrossRef]

30. Schmid, P.; Adams, S.; Rugo, H.S.; Schneeweiss, A.; Barrios, C.H.; Iwata, H.; Diéras, V.; Hegg, R.; Im, S.-A.; Shaw Wright, G.; et al. Atezolizumab and Nab-Paclitaxel in Advanced Triple-Negative Breast Cancer. N. Engl. J. Med. 2018, 379, 2108-2121. [CrossRef]

31. Miles, D.; Gligorov, J.; André, F.; Cameron, D.; Schneeweiss, A.; Barrios, C.; Xu, B.; Wardley, A.; Kaen, D.; Andrade, L.; et al Primary Results from IMpassion131, a Double-Blind, Placebo-Controlled, Randomised Phase III Trial of First-Line Paclitaxel with or without Atezolizumab for Unresectable Locally Advanced/Metastatic Triple-Negative Breast Cancer. Ann. Oncol. 2021, 32, 994-1004. [CrossRef] [PubMed] 
32. Cortes, J.; Cescon, D.W.; Rugo, H.S.; Nowecki, Z.; Im, S.-A.; Yusof, M.M.; Gallardo, C.; Lipatov, O.; Barrios, C.H.; Holgado, E.; et al. Pembrolizumab plus Chemotherapy versus Placebo plus Chemotherapy for Previously Untreated Locally Recurrent Inoperable or Metastatic Triple-Negative Breast Cancer (KEYNOTE-355): A Randomised, Placebo-Controlled, Double-Blind, Phase 3 Clinical Trial. Lancet 2020, 396, 1817-1828. [CrossRef]

33. Schmid, P.; Salgado, R.; Park, Y.H.; Muñoz-Couselo, E.; Kim, S.B.; Sohn, J.; Im, S.-A.; Foukakis, T.; Kuemmel, S.; Dent, R.; et al. Pembrolizumab plus Chemotherapy as Neoadjuvant Treatment of High-Risk, Early-Stage Triple-Negative Breast Cancer: Results from the Phase 1b Open-Label, Multicohort KEYNOTE-173 Study. Ann. Oncol. 2020, 31, 569-581. [CrossRef] [PubMed]

34. Nanda, R.; Liu, M.C.; Yau, C.; Shatsky, R.; Pusztai, L.; Wallace, A.; Chien, A.J.; Forero-Torres, A.; Ellis, E.; Han, H.; et al. Effect of Pembrolizumab Plus Neoadjuvant Chemotherapy on Pathologic Complete Response in Women With Early-Stage Breast Cancer: An Analysis of the Ongoing Phase 2 Adaptively Randomized I-SPY2 Trial. JAMA Oncol. 2020, 6, 676-684. [CrossRef] [PubMed]

35. Loibl, S.; Untch, M.; Burchardi, N.; Huober, J.; Sinn, B.V.; Blohmer, J.-U.; Grischke, E.-M.; Furlanetto, J.; Tesch, H.; Hanusch, C.; et al. A Randomised Phase II Study Investigating Durvalumab in Addition to an Anthracycline Taxane-Based Neoadjuvant Therapy in Early Triple-Negative Breast Cancer: Clinical Results and Biomarker Analysis of GeparNuevo Study. Ann. Oncol. 2019, 30, 1279-1288. [CrossRef] [PubMed]

36. Loibl, S.; Schneeweiss, A.; Huober, J.B.; Braun, M.; Rey, J.; Blohmer, J.U.; Furlanetto, J.; Zahm, D.M.; Hanusch, C.; Thomalla, J.; et al. Durvalumab Improves Long-Term Outcome in TNBC: Results from the Phase II Randomized GeparNUEVO Study Investigating Neodjuvant Durvalumab in Addition to an Anthracycline/Taxane Based Neoadjuvant Chemotherapy in Early Triple-Negative Breast Cancer (TNBC). JCO 2021, 39, 506. [CrossRef]

37. Mittendorf, E.A.; Zhang, H.; Barrios, C.H.; Saji, S.; Jung, K.H.; Hegg, R.; Koehler, A.; Sohn, J.; Iwata, H.; Telli, M.L.; et al. Neoadjuvant Atezolizumab in Combination with Sequential Nab-Paclitaxel and Anthracycline-Based Chemotherapy versus Placebo and Chemotherapy in Patients with Early-Stage Triple-Negative Breast Cancer (IMpassion031): A Randomised, DoubleBlind, Phase 3 Trial. Lancet 2020, 396, 1090-1100. [CrossRef]

38. Schmid, P.; Cortes, J.; Pusztai, L.; McArthur, H.; Kümmel, S.; Bergh, J.; Denkert, C.; Park, Y.H.; Hui, R.; Harbeck, N.; et al. Pembrolizumab for Early Triple-Negative Breast Cancer. N. Engl. J. Med. 2020, 382, 810-821. [CrossRef]

39. Gianni, L.; Huang, C.-S.; Egle, D.; Bermejo, B.; Zamagni, C.; Thill, M.; Anton, A.; Zambelli, S.; Bianchini, G.; Russo, S.; et al. Abstract GS3-04: Pathologic Complete Response (PCR) to Neoadjuvant Treatment with or without Atezolizumab in Triple Negative, Early High-Risk and Locally Advanced Breast Cancer. NeoTRIPaPDL1 Michelangelo Randomized Study. Cancer Res. 2020, 80, GS3-04.

40. Lüönd, F.; Tiede, S.; Christofori, G. Breast Cancer as an Example of Tumour Heterogeneity and Tumour Cell Plasticity during Malignant Progression. Br. J. Cancer 2021, 1-12. [CrossRef]

41. Salemme, V.; Centonze, G.; Cavallo, F.; Defilippi, P.; Conti, L. The Crosstalk Between Tumor Cells and the Immune Microenvironment in Breast Cancer: Implications for Immunotherapy. Front. Oncol. 2021, 11, 289. [CrossRef]

42. Karn, T.; Jiang, T.; Hatzis, C.; Sänger, N.; El-Balat, A.; Rody, A.; Holtrich, U.; Becker, S.; Bianchini, G.; Pusztai, L. Association Between Genomic Metrics and Immune Infiltration in Triple-Negative Breast Cancer. JAMA Oncol. 2017, 3, 1707-1711. [CrossRef]

43. Szekely, B.; Bossuyt, V.; Li, X.; Wali, V.B.; Patwardhan, G.A.; Frederick, C.; Silber, A.; Park, T.; Harigopal, M.; Pelekanou, V.; et al. Immunological Differences between Primary and Metastatic Breast Cancer. Ann. Oncol. 2018, 29, 2232-2239. [CrossRef] [PubMed]

44. Hodge, J.W.; Garnett, C.T.; Farsaci, B.; Palena, C.; Tsang, K.-Y.; Ferrone, S.; Gameiro, S.R. Chemotherapy-Induced Immunogenic Modulation of Tumor Cells Enhances Killing by Cytotoxic T Lymphocytes and Is Distinct from Immunogenic Cell Death. Int. J. Cancer 2013, 133, 624-636. [CrossRef] [PubMed]

45. Voorwerk, L.; Slagter, M.; Horlings, H.M.; Sikorska, K.; van de Vijver, K.K.; de Maaker, M.; Nederlof, I.; Kluin, R.J.C.; Warren, S.; Ong, S.; et al. Immune Induction Strategies in Metastatic Triple-Negative Breast Cancer to Enhance the Sensitivity to PD-1 Blockade: The TONIC Trial. Nat. Med. 2019, 25, 920-928. [CrossRef] [PubMed]

46. Bonaventura, P.; Shekarian, T.; Alcazer, V.; Valladeau-Guilemond, J.; Valsesia-Wittmann, S.; Amigorena, S.; Caux, C.; Depil, S. Cold Tumors: A Therapeutic Challenge for Immunotherapy. Front. Immunol. 2019, 10, 168. [CrossRef]

47. Esteva, F.J.; Hubbard-Lucey, V.M.; Tang, J.; Pusztai, L. Immunotherapy and Targeted Therapy Combinations in Metastatic Breast Cancer. Lancet Oncol. 2019, 20, e175-e186. [CrossRef]

48. Duan, Q.; Zhang, H.; Zheng, J.; Zhang, L. Turning Cold into Hot: Firing up the Tumor Microenvironment. Trends Cancer 2020, 6, 605-618. [CrossRef]

49. Hegde, P.S.; Chen, D.S. Top 10 Challenges in Cancer Immunotherapy. Immunity 2020, 52, 17-35. [CrossRef] [PubMed]

50. Barroso-Sousa, R.; Jain, E.; Cohen, O.; Kim, D.; Buendia-Buendia, J.; Winer, E.; Lin, N.; Tolaney, S.M.; Wagle, N. Prevalence and Mutational Determinants of High Tumor Mutation Burden in Breast Cancer. Ann. Oncol. 2020, 31, 387-394. [CrossRef] [PubMed]

51. Shin, D.S.; Zaretsky, J.M.; Escuin-Ordinas, H.; Garcia-Diaz, A.; Hu-Lieskovan, S.; Kalbasi, A.; Grasso, C.S.; Hugo, W.; Sandoval, S.; Torrejon, D.Y.; et al. Primary Resistance to PD-1 Blockade Mediated by JAK1/2 Mutations. Cancer Discov. 2017, 7, 188-201. [CrossRef] [PubMed]

52. Kim, J.Y.; Kronbichler, A.; Eisenhut, M.; Hong, S.H.; van der Vliet, H.J.; Kang, J.; Shin, J.I.; Gamerith, G. Tumor Mutational Burden and Efficacy of Immune Checkpoint Inhibitors: A Systematic Review and Meta-Analysis. Cancers 2019, 11, 1798. [CrossRef] [PubMed] 
53. Gettinger, S.; Choi, J.; Hastings, K.; Truini, A.; Datar, I.; Sowell, R.; Wurtz, A.; Dong, W.; Cai, G.; Melnick, M.A.; et al. Impaired HLA Class I Antigen Processing and Presentation as a Mechanism of Acquired Resistance to Immune Checkpoint Inhibitors in Lung Cancer. Cancer Discov. 2017, 7, 1420-1435. [CrossRef]

54. Chowell, D.; Morris, L.G.T.; Grigg, C.M.; Weber, J.K.; Samstein, R.M.; Makarov, V.; Kuo, F.; Kendall, S.M.; Requena, D.; Riaz, N.; et al. Patient HLA Class I Genotype Influences Cancer Response to Checkpoint Blockade Immunotherapy. Science 2018, 359, 582-587. [CrossRef] [PubMed]

55. De kruijf, E.; van Nes, J.; Sajet, A.; Tummers, Q.; Putter, H.; Osanto, S.; Speetjens, F.; Smit, V.; Liefers, G.-J.; Velde, C.; et al. The Predictive Value of HLA Class I Tumor Cell Expression and Presence of Intratumoral Tregs for Chemotherapy in Patients with Early Breast Cancer. Clin. Cancer Res. Off. J. Am. Assoc. Cancer Res. 2010, 16, 1272-1280. [CrossRef] [PubMed]

56. Chen, D.S.; Mellman, I. Elements of Cancer Immunity and the Cancer-Immune Set Point. Nature 2017, 541, 321-330. [CrossRef] [PubMed]

57. Sade-Feldman, M.; Jiao, Y.J.; Chen, J.H.; Rooney, M.S.; Barzily-Rokni, M.; Eliane, J.-P.; Bjorgaard, S.L.; Hammond, M.R.; Vitzthum, H.; Blackmon, S.M.; et al. Resistance to Checkpoint Blockade Therapy through Inactivation of Antigen Presentation. Nat. Commun. 2017, 8, 1136. [CrossRef] [PubMed]

58. Cristescu, R.; Mogg, R.; Ayers, M.; Albright, A.; Murphy, E.; Yearley, J.; Sher, X.; Liu, X.Q.; Lu, H.; Nebozhyn, M.; et al. Pan-Tumor Genomic Biomarkers for PD-1 Checkpoint Blockade-Based Immunotherapy. Science 2018, 362, eaar3593. [CrossRef]

59. Galluzzi, L.; Buqué, A.; Kepp, O.; Zitvogel, L.; Kroemer, G. Immunogenic Cell Death in Cancer and Infectious Disease. Nat. Rev. Immunol. 2017, 17, 97-111. [CrossRef] [PubMed]

60. Ding, L.; Kim, H.-J.; Wang, Q.; Kearns, M.; Jiang, T.; Ohlson, C.E.; Li, B.B.; Xie, S.; Liu, J.F.; Stover, E.H.; et al. PARP Inhibition Elicits STING-Dependent Antitumor Immunity in Brca1-Deficient Ovarian Cancer. Cell Rep. 2018, 25, 2972-2980.e5. [CrossRef]

61. Pantelidou, C.; Sonzogni, O.; De Oliveria Taveira, M.; Mehta, A.K.; Kothari, A.; Wang, D.; Visal, T.; Li, M.K.; Pinto, J.; Castrillon, J.A.; et al. PARP Inhibitor Efficacy Depends on CD8+ T-Cell Recruitment via Intratumoral STING Pathway Activation in BRCA-Deficient Models of Triple-Negative Breast Cancer. Cancer Discov. 2019, 9, 722-737. [CrossRef] [PubMed]

62. Wen, W.X.; Leong, C.-O. Association of BRCA1- and BRCA2-Deficiency with Mutation Burden, Expression of PD-L1/PD-1, Immune Infiltrates, and T Cell-Inflamed Signature in Breast Cancer. PLoS ONE 2019, 14, e215381. [CrossRef] [PubMed]

63. Jiao, S.; Xia, W.; Yamaguchi, H.; Wei, Y.; Chen, M.-K.; Hsu, J.-M.; Hsu, J.L.; Yu, W.-H.; Du, Y.; Lee, H.-H.; et al. PARP Inhibitor Upregulates PD-L1 Expression and Enhances Cancer-Associated Immunosuppression. Clin. Cancer Res. 2017, 23, 3711-3720. [CrossRef]

64. Sato, H.; Niimi, A.; Yasuhara, T.; Permata, T.B.M.; Hagiwara, Y.; Isono, M.; Nuryadi, E.; Sekine, R.; Oike, T.; Kakoti, S.; et al. DNA Double-Strand Break Repair Pathway Regulates PD-L1 Expression in Cancer Cells. Nat. Commun. 2017, 8, 1-11. [CrossRef]

65. Sen, T.; Rodriguez, B.L.; Chen, L.; Corte, C.M.D.; Morikawa, N.; Fujimoto, J.; Cristea, S.; Nguyen, T.; Diao, L.; Li, L.; et al. Targeting DNA Damage Response Promotes Antitumor Immunity through STING-Mediated T-Cell Activation in Small Cell Lung Cancer. Cancer Discov. 2019, 9, 646-661. [CrossRef] [PubMed]

66. Domchek, S.M.; Postel-Vinay, S.; Im, S.-A.; Park, Y.H.; Delord, J.-P.; Italiano, A.; Alexandre, J.; You, B.; Bastian, S.; Krebs, M.G.; et al. Olaparib and Durvalumab in Patients with Germline BRCA-Mutated Metastatic Breast Cancer (MEDIOLA): An Open-Label, Multicentre, Phase 1/2, Basket Study. Lancet Oncol. 2020, 21, 1155-1164. [CrossRef]

67. Vinayak, S.; Tolaney, S.M.; Schwartzberg, L.S.; Mita, M.M.; McCann, G.A.-L.; Tan, A.R.; Wahner Hendrickson, A.E.; Forero-Torres, A.; Anders, C.K.; Wulf, G.M.; et al. TOPACIO/Keynote-162: Niraparib + Pembrolizumab in Patients (Pts) with Metastatic Triple-Negative Breast Cancer (TNBC), a Phase 2 Trial. JCO 2018, 36, 1011. [CrossRef]

68. Hu-Lieskovan, S.; Mok, S.; Moreno, B.H.; Tsoi, J.; Faja, L.R.; Goedert, L.; Pinheiro, E.M.; Koya, R.C.; Graeber, T.; Comin-Anduix, B.; et al. Improved Antitumor Activity of Immunotherapy with BRAF and MEK Inhibitors in BRAFV600E Melanoma. Sci. Transl. Med. 2015, 7, 279ra41. [CrossRef]

69. Ebert, P.J.R.; Cheung, J.; Yang, Y.; McNamara, E.; Hong, R.; Moskalenko, M.; Gould, S.E.; Maecker, H.; Irving, B.A.; Kim, J.M.; et al. MAP Kinase Inhibition Promotes T Cell and Anti-Tumor Activity in Combination with PD-L1 Checkpoint Blockade. Immunity 2016, 44, 609-621. [CrossRef] [PubMed]

70. Loi, S.; Dushyanthen, S.; Beavis, P.A.; Salgado, R.; Denkert, C.; Savas, P.; Combs, S.; Rimm, D.L.; Giltnane, J.M.; Estrada, M.V.; et al. RAS/MAPK Activation Is Associated with Reduced Tumor-Infiltrating Lymphocytes in Triple-Negative Breast Cancer: Therapeutic Cooperation between MEK and PD-1/PD-L1 Immune Checkpoint Inhibitors. Clin. Cancer Res. 2016, 22, 1499-1509. [CrossRef] [PubMed]

71. Franklin, D.A.; James, J.L.; Axelrod, M.L.; Balko, J.M. MEK Inhibition Activates STAT Signaling to Increase Breast Cancer Immunogenicity via MHC-I Expression. Cancer Drug Resist. 2020, 3, 603-612. [CrossRef]

72. Brufsky, A.; Kim, S.B.; Zvirbule, Ž.; Eniu, A.; Mebis, J.; Sohn, J.H.; Wongchenko, M.; Chohan, S.; Amin, R.; Yan, Y.; et al. A Phase II Randomized Trial of Cobimetinib plus Chemotherapy, with or without Atezolizumab, as First-Line Treatment for Patients with Locally Advanced or Metastatic Triple-Negative Breast Cancer (COLET): Primary Analysis. Ann. Oncol. 2021, 32, 652-660. [CrossRef]

73. Dushyanthen, S.; Teo, Z.L.; Caramia, F.; Savas, P.; Mintoff, C.P.; Virassamy, B.; Henderson, M.A.; Luen, S.J.; Mansour, M.; Kershaw, M.H.; et al. Agonist Immunotherapy Restores T Cell Function Following MEK Inhibition Improving Efficacy in Breast Cancer. Nat. Commun. 2017, 8, 606. [CrossRef] [PubMed] 
74. Schmid, P.; Forster, M.D.; Summers, Y.J.; Good, J.; Sarker, S.-J.; Lim, L.; Mousa, K.; Middleton, G.W. A Study of Vistusertib in Combination with Selumetinib in Patients with Advanced Cancers: TORCMEK Phase Ib Results. JCO 2017, 35, 2548. [CrossRef]

75. Li, J.; Huo, X.; Zhao, F.; Ren, D.; Ahmad, R.; Yuan, X.; Du, F.; Zhao, J. Association of Cyclin-Dependent Kinases 4 and 6 Inhibitors With Survival in Patients With Hormone Receptor-Positive Metastatic Breast Cancer: A Systematic Review and Meta-Analysis. JAMA Netw. Open 2020, 3, e2020312. [CrossRef] [PubMed]

76. Goel, S.; DeCristo, M.J.; Watt, A.C.; BrinJones, H.; Sceneay, J.; Li, B.B.; Khan, N.; Ubellacker, J.M.; Xie, S.; Metzger-Filho, O.; et al CDK4/ 6 Inhibition Triggers Anti-Tumour Immunity. Nature 2017, 548, 471-475. [CrossRef] [PubMed]

77. Deng, J.; Wang, E.S.; Jenkins, R.W.; Li, S.; Dries, R.; Yates, K.; Chhabra, S.; Huang, W.; Liu, H.; Aref, A.R.; et al. CDK4/6 Inhibition Augments Antitumor Immunity by Enhancing T-Cell Activation. Cancer Discov. 2018, 8, 216-233. [CrossRef]

78. Lai, A.Y.; Sorrentino, J.A.; Dragnev, K.H.; Weiss, J.M.; Owonikoko, T.K.; Rytlewski, J.A.; Hood, J.; Yang, Z.; Malik, R.K.; Strum, J.C.; et al. CDK4/6 Inhibition Enhances Antitumor Efficacy of Chemotherapy and Immune Checkpoint Inhibitor Combinations in Preclinical Models and Enhances T-Cell Activation in Patients with SCLC Receiving Chemotherapy. J. Immunother. Cancer 2020, 8, e000847. [CrossRef] [PubMed]

79. Rugo, H.S.; Kabos, P.; Beck, J.T.; Chisamore, M.J.; Hossain, A.; Chen, Y.; Tolaney, S.M. A Phase Ib Study of Abemaciclib in Combination with Pembrolizumab for Patients with Hormone Receptor Positive (HR+), Human Epidermal Growth Factor Receptor 2 Negative (HER2-) Locally Advanced or Metastatic Breast Cancer (MBC) (NCT02779751): Interim Results. JCO 2020, 38, 1051. [CrossRef]

80. Meric-Bernstam, F.; Larkin, J.; Tabernero, J.; Bonini, C. Enhancing Anti-Tumour Efficacy with Immunotherapy Combinations. Int. J. STD AIDS 2021, 397, 1010-1022. [CrossRef]

81. Chikuma, S. CTLA-4, an Essential Immune-Checkpoint for T-Cell Activation. Curr Top. Microbiol. Immunol. 2017, 410, 99-126. [CrossRef] [PubMed]

82. Rotte, A. Combination of CTLA-4 and PD-1 Blockers for Treatment of Cancer. J. Exp. Clin. Cancer Res. 2019, 38, 255. [CrossRef] [PubMed]

83. Santa-Maria, C.A.; Kato, T.; Park, J.-H.; Kiyotani, K.; Rademaker, A.; Shah, A.N.; Gross, L.; Blanco, L.Z.; Jain, S.; Flaum, L.; et al. A Pilot Study of Durvalumab and Tremelimumab and Immunogenomic Dynamics in Metastatic Breast Cancer. Oncotarget 2018, 9, 18985-18996. [CrossRef] [PubMed]

84. Dahlén, E.; Veitonmäki, N.; Norlén, P. Bispecific Antibodies in Cancer Immunotherapy. Adv. Vaccines Immunother. 2018, 6, 3-17. [CrossRef] [PubMed]

85. Gennari, R.; Menard, S.; Fagnoni, F.; Ponchio, L.; Scelsi, M.; Tagliabue, E.; Castiglioni, F.; Villani, L.; Magalotti, C.; Gibelli, N.; et al. Pilot Study of the Mechanism of Action of Preoperative Trastuzumab in Patients with Primary Operable Breast Tumors Overexpressing HER2. Clin. Cancer Res. 2004, 10, 5650-5655. [CrossRef] [PubMed]

86. Arnould, L.; Gelly, M.; Penault-Llorca, F.; Benoit, L.; Bonnetain, F.; Migeon, C.; Cabaret, V.; Fermeaux, V.; Bertheau, P.; Garnier, J.; et al. Trastuzumab-Based Treatment of HER2-Positive Breast Cancer: An Antibody-Dependent Cellular Cytotoxicity Mechanism? Br. J. Cancer 2006, 94, 259-267. [CrossRef]

87. Holgado, E.; Perez-Garcia, J.; Gion, M.; Cortes, J. Is There a Role for Immunotherapy in HER2-Positive Breast Cancer? NPJ Breast Cancer 2018, 4, 21. [CrossRef]

88. Müller, P.; Kreuzaler, M.; Khan, T.; Thommen, D.S.; Martin, K.; Glatz, K.; Savic, S.; Harbeck, N.; Nitz, U.; Gluz, O.; et al. Trastuzumab Emtansine (T-DM1) Renders HER2+ Breast Cancer Highly Susceptible to CTLA-4/PD-1 Blockade. Sci. Transl. Med. 2015, 7, 315ra188. [CrossRef] [PubMed]

89. Stagg, J.; Loi, S.; Divisekera, U.; Ngiow, S.F.; Duret, H.; Yagita, H.; Teng, M.W.; Smyth, M.J. Anti-ErbB-2 MAb Therapy Requires Type I and II Interferons and Synergizes with Anti-PD-1 or Anti-CD137 MAb Therapy. Proc. Natl. Acad. Sci. USA 2011, 108, 7142-7147. [CrossRef] [PubMed]

90. Loi, S.; Giobbie-Hurder, A.; Gombos, A.; Bachelot, T.; Hui, R.; Curigliano, G.; Campone, M.; Biganzoli, L.; Bonnefoi, H.; Jerusalem, G.; et al. Pembrolizumab plus Trastuzumab in Trastuzumab-Resistant, Advanced, HER2-Positive Breast Cancer (PANACEA): A Single-Arm, Multicentre, Phase 1b-2 Trial. Lancet Oncol. 2019, 20, 371-382. [CrossRef]

91. Emens, L.A.; Esteva, F.J.; Beresford, M.; Saura, C.; De Laurentiis, M.; Kim, S.-B.; Im, S.-A.; Wang, Y.; Salgado, R.; Mani, A.; et al. Trastuzumab Emtansine plus Atezolizumab versus Trastuzumab Emtansine plus Placebo in Previously Treated, HER2-Positive Advanced Breast Cancer (KATE2): A Phase 2, Multicentre, Randomised, Double-Blind Trial. Lancet Oncol. 2020, 21, $1283-1295$. [CrossRef]

92. Casares, N.; Pequignot, M.O.; Tesniere, A.; Ghiringhelli, F.; Roux, S.; Chaput, N.; Schmitt, E.; Hamai, A.; Hervas-Stubbs, S.; Obeid, M.; et al. Caspase-Dependent Immunogenicity of Doxorubicin-Induced Tumor Cell Death. J. Exp. Med. 2005, 202, 1691-1701. [CrossRef] [PubMed]

93. Apetoh, L.; Mignot, G.; Panaretakis, T.; Kroemer, G.; Zitvogel, L. Immunogenicity of Anthracyclines: Moving towards More Personalized Medicine. Trends Mol. Med. 2008, 14, 141-151. [CrossRef] [PubMed]

94. Aoto, K.; Mimura, K.; Okayama, H.; Saito, M.; Chida, S.; Noda, M.; Nakajima, T.; Saito, K.; Abe, N.; Ohki, S.; et al. Immunogenic Tumor Cell Death Induced by Chemotherapy in Patients with Breast Cancer and Esophageal Squamous Cell Carcinoma. Oncol. Rep. 2018, 39, 151-159. [CrossRef] [PubMed] 
95. Apetoh, L.; Ghiringhelli, F.; Tesniere, A.; Obeid, M.; Ortiz, C.; Criollo, A.; Mignot, G.; Maiuri, M.C.; Ullrich, E.; Saulnier, P.; et al. Toll-like Receptor 4-Dependent Contribution of the Immune System to Anticancer Chemotherapy and Radiotherapy. Nat. Med. 2007, 13, 1050-1059. [CrossRef] [PubMed]

96. Ladoire, S.; Enot, D.; Senovilla, L.; Ghiringhelli, F.; Poirier-Colame, V.; Chaba, K.; Semeraro, M.; Chaix, M.; Penault-Llorca, F.; Arnould, L.; et al. The Presence of LC3B Puncta and HMGB1 Expression in Malignant Cells Correlate with the Immune Infiltrate in Breast Cancer. Autophagy 2016, 12, 864-875. [CrossRef] [PubMed]

97. D' Amico, L.; Menzel, U.; Prummer, M.; Müller, P.; Buchi, M.; Kashyap, A.; Haessler, U.; Yermanos, A.; Gébleux, R.; Briendl, M.; et al. A Novel Anti-HER2 Anthracycline-Based Antibody-Drug Conjugate Induces Adaptive Anti-Tumor Immunity and Potentiates PD-1 Blockade in Breast Cancer. J. Immunother. Cancer 2019, 7, 16. [CrossRef] [PubMed]

98. Gebremeskel, S.; Lobert, L.; Tanner, K.; Walker, B.; Oliphant, T.; Clarke, L.E.; Dellaire, G.; Johnston, B. Natural Killer T-Cell Immunotherapy in Combination with Chemotherapy-Induced Immunogenic Cell Death Targets Metastatic Breast Cancer. Cancer Immunol. Res. 2017, 5, 1086-1097. [CrossRef] [PubMed]

99. Sistigu, A.; Yamazaki, T.; Vacchelli, E.; Chaba, K.; Enot, D.P.; Adam, J.; Vitale, I.; Goubar, A.; Baracco, E.E.; Remédios, C.; et al. Cancer Cell-Autonomous Contribution of Type I Interferon Signaling to the Efficacy of Chemotherapy. Nat. Med. 2014, 20, 1301-1309. [CrossRef] [PubMed]

100. Litchfield, K.; Reading, J.L.; Puttick, C.; Thakkar, K.; Abbosh, C.; Bentham, R.; Watkins, T.B.K.; Rosenthal, R.; Biswas, D.; Rowan, A.; et al. Meta-Analysis of Tumor- and T Cell-Intrinsic Mechanisms of Sensitization to Checkpoint Inhibition. Cell 2021, 184, 596-614.e14. [CrossRef] [PubMed]

101. Ludgate, C.M. Optimizing Cancer Treatments to Induce an Acute Immune Response: Radiation Abscopal Effects, PAMPs, and DAMPs. Clin. Cancer Res. 2012, 18, 4522-4525. [CrossRef] [PubMed]

102. Twyman-Saint Victor, C.; Rech, A.J.; Maity, A.; Rengan, R.; Pauken, K.E.; Stelekati, E.; Benci, J.L.; Xu, B.; Dada, H.; Odorizzi, P.M.; et al. Radiation and Dual Checkpoint Blockade Activate Non-Redundant Immune Mechanisms in Cancer. Nature 2015, 520, 373-377. [CrossRef]

103. Dovedi, S.J.; Adlard, A.L.; Lipowska-Bhalla, G.; McKenna, C.; Jones, S.; Cheadle, E.J.; Stratford, I.J.; Poon, E.; Morrow, M.; Stewart, R.; et al. Acquired Resistance to Fractionated Radiotherapy Can Be Overcome by Concurrent PD-L1 Blockade. Cancer Res. 2014, 74, 5458-5468. [CrossRef] [PubMed]

104. Antonia, S.J.; Villegas, A.; Daniel, D.; Vicente, D.; Murakami, S.; Hui, R.; Yokoi, T.; Chiappori, A.; Lee, K.H.; de Wit, M.; et al. Durvalumab after Chemoradiotherapy in Stage III Non-Small-Cell Lung Cancer. N. Engl. J. Med. 2017, 377, 1919-1929. [CrossRef] [PubMed]

105. Cao, K.; Abbassi, L.; Romano, E.; Kirova, Y. Radiation Therapy and Immunotherapy in Breast Cancer Treatment: Preliminary Data and Perspectives. Expert Rev. Anticancer 2021, 21, 501-510. [CrossRef]

106. Ho, A.Y.; Barker, C.A.; Arnold, B.B.; Powell, S.N.; Hu, Z.I.; Gucalp, A.; Lebron-Zapata, L.; Wen, H.Y.; Kallman, C.; D’Agnolo, A.; et al. A Phase 2 Clinical Trial assessing the efficacy and Safety of Pembrolizumab and Radiotherapy in Patients with Metastatic Triple-Negative Breast Cancer. Cancer 2020, 126, 850-860. [CrossRef]

107. Hu, Z.I.; McArthur, H.L.; Ho, A.Y. The Abscopal Effect of Radiation Therapy: What Is It and How Can We Use It in Breast Cancer? Curr. Breast Cancer Rep. 2017, 9, 45-51. [CrossRef] [PubMed]

108. Crocenzi, T.; Cottam, B.; Newell, P.; Wolf, R.F.; Hansen, P.D.; Hammill, C.; Solhjem, M.C.; To, Y.-Y.; Greathouse, A.; Tormoen, G.; et al. A Hypofractionated Radiation Regimen Avoids the Lymphopenia Associated with Neoadjuvant Chemoradiation Therapy of Borderline Resectable and Locally Advanced Pancreatic Adenocarcinoma. J. Immunother. Cancer 2016, 4, 45. [CrossRef]

109. Morisada, M.; Clavijo, P.E.; Moore, E.; Sun, L.; Chamberlin, M.; Van Waes, C.; Hodge, J.W.; Mitchell, J.B.; Friedman, J.; Allen, C.T. PD-1 Blockade Reverses Adaptive Immune Resistance Induced by High-Dose Hypofractionated but Not Low-Dose Daily Fractionated Radiation. Oncoimmunology 2018, 7, e1395996. [CrossRef] [PubMed]

110. Demaria, S.; Coleman, C.N.; Formenti, S.C. Radiotherapy: Changing the Game in Immunotherapy. Trends Cancer 2016, 2, 286-294. [CrossRef] [PubMed]

111. Corrales, L.; Gajewski, T.F. Molecular Pathways: Targeting the Stimulator of Interferon Genes (STING) in the Immunotherapy of Cancer. Clin. Cancer Res. 2015, 21, 4774-4779. [CrossRef] [PubMed]

112. Cheng, N.; Watkins-Schulz, R.; Junkins, R.D.; David, C.N.; Johnson, B.M.; Montgomery, S.A.; Peine, K.J.; Darr, D.B.; Yuan, H.; McKinnon, K.P.; et al. A Nanoparticle-Incorporated STING Activator Enhances Antitumor Immunity in PD-L1-Insensitive Models of Triple-Negative Breast Cancer. JCI Insight 2018, 3, 120638. [CrossRef] [PubMed]

113. Corrales, L.; Glickman, L.H.; McWhirter, S.M.; Kanne, D.B.; Sivick, K.E.; Katibah, G.E.; Woo, S.-R.; Lemmens, E.; Banda, T.; Leong, J.J.; et al. Direct Activation of STING in the Tumor Microenvironment Leads to Potent and Systemic Tumor Regression and Immunity. Cell Rep. 2015, 11, 1018-1030. [CrossRef]

114. Wang, H.; Hu, S.; Chen, X.; Shi, H.; Chen, C.; Sun, L.; Chen, Z.J. CGAS Is Essential for the Antitumor Effect of Immune Checkpoint Blockade. Proc. Natl. Acad. Sci. USA 2017, 114, 1637-1642. [CrossRef]

115. Pantelidou, C.; Jadhav, H.; Kothari, A.; Liu, R.; Guerriero, J.L.; Shapiro, G.I. STING Agonism Enhances Anti-Tumor Immune Responses and Therapeutic Efficacy of PARP Inhibition in BRCA-Associated Breast Cancer. bioRxiv 2021. [CrossRef]

116. Ghiringhelli, F.; Larmonier, N.; Schmitt, E.; Parcellier, A.; Cathelin, D.; Garrido, C.; Chauffert, B.; Solary, E.; Bonnotte, B.; Martin, F. CD4+CD25+ Regulatory T Cells Suppress Tumor Immunity but Are Sensitive to Cyclophosphamide Which Allows Immunotherapy of Established Tumors to Be Curative. Eur. J. Immunol. 2004, 34, 336-344. [CrossRef] [PubMed] 
117. Vincent, J.; Mignot, G.; Chalmin, F.; Ladoire, S.; Bruchard, M.; Chevriaux, A.; Martin, F.; Apetoh, L.; Rébé, C.; Ghiringhelli, F. 5-Fluorouracil Selectively Kills Tumor-Associated Myeloid-Derived Suppressor Cells Resulting in Enhanced T Cell-Dependent Antitumor Immunity. Cancer Res. 2010, 70, 3052-3061. [CrossRef] [PubMed]

118. Khan, K.A.; Ponce de Léon, J.L.; Benguigui, M.; Xu, P.; Chow, A.; Cruz-Muñoz, W.; Man, S.; Shaked, Y.; Kerbel, R.S. Immunostimulatory and Anti-Tumor Metronomic Cyclophosphamide Regimens Assessed in Primary Orthotopic and Metastatic Murine Breast Cancer. NPJ Breast Cancer 2020, 6, 1-13. [CrossRef]

119. Wanderley, C.W.; Colón, D.F.; Luiz, J.P.M.; Oliveira, F.F.; Viacava, P.R.; Leite, C.A.; Pereira, J.A.; Silva, C.M.; Silva, C.R.; Silva, R.L.; et al. Paclitaxel Reduces Tumor Growth by Reprogramming Tumor-Associated Macrophages to an M1 Profile in a TLR4-Dependent Manner. Cancer Res. 2018, 78, 5891-5900. [CrossRef] [PubMed]

120. Michels, T.; Shurin, G.V.; Naiditch, H.; Sevko, A.; Umansky, V.; Shurin, M.R. Paclitaxel Promotes Differentiation of MyeloidDerived Suppressor Cells into Dendritic Cells in Vitro in a TLR4-Independent Manner. J. Immunotoxicol. 2012, 9, 292-300. [CrossRef] [PubMed]

121. Munn, D.H. Indoleamine 2,3-Dioxygenase, Tregs and Cancer. Curr. Med. Chem. 2011, 18, 2240-2246. [CrossRef] [PubMed]

122. Soliman, H.H.; Jackson, E.; Neuger, T.; Dees, E.C.; Harvey, R.D.; Han, H.; Ismail-Khan, R.; Minton, S.; Vahanian, N.N.; Link, C.; et al. A First in Man Phase I Trial of the Oral Immunomodulator, Indoximod, Combined with Docetaxel in Patients with Metastatic Solid Tumors. Oncotarget 2014, 5, 8136-8146. [CrossRef]

123. Mitchell, T.C.; Hamid, O.; Smith, D.C.; Bauer, T.M.; Wasser, J.S.; Olszanski, A.J.; Luke, J.J.; Balmanoukian, A.S.; Schmidt, E.V.; Zhao, Y.; et al. Epacadostat Plus Pembrolizumab in Patients With Advanced Solid Tumors: Phase I Results From a Multicenter, Open-Label Phase I/II Trial (ECHO-202/KEYNOTE-037). JCO 2018, 36, 3223-3230. [CrossRef] [PubMed]

124. Beavis, P.A.; Stagg, J.; Darcy, P.K.; Smyth, M.J. CD73: A Potent Suppressor of Antitumor Immune Responses. Trends Immunol. 2012, 33, 231-237. [CrossRef] [PubMed]

125. Beavis, P.A.; Divisekera, U.; Paget, C.; Chow, M.T.; John, L.B.; Devaud, C.; Dwyer, K.; Stagg, J.; Smyth, M.J.; Darcy, P.K. Blockade of A2A Receptors Potently Suppresses the Metastasis of CD73+ Tumors. Proc. Natl. Acad. Sci. USA 2013, 110, 14711-14716. [CrossRef] [PubMed]

126. Loi, S.; Pommey, S.; Haibe-Kains, B.; Beavis, P.A.; Darcy, P.K.; Smyth, M.J.; Stagg, J. CD73 Promotes Anthracycline Resistance and Poor Prognosis in Triple Negative Breast Cancer. Proc. Natl. Acad. Sci. USA 2013, 110, 11091-11096. [CrossRef]

127. Mittal, D.; Young, A.; Stannard, K.; Yong, M.; Teng, M.W.L.; Allard, B.; Stagg, J.; Smyth, M.J. Antimetastatic Effects of Blocking PD-1 and the Adenosine A2A Receptor. Cancer Res. 2014, 74, 3652-3658. [CrossRef]

128. Peng, W.; Chen, J.Q.; Liu, C.; Malu, S.; Creasy, C.; Tetzlaff, M.T.; Xu, C.; McKenzie, J.A.; Zhang, C.; Liang, X.; et al. Loss of PTEN Promotes Resistance to T Cell-Mediated Immunotherapy. Cancer Discov. 2016, 6, 202-216. [CrossRef] [PubMed]

129. Lastwika, K.J.; Wilson, W.; Li, Q.K.; Norris, J.; Xu, H.; Ghazarian, S.R.; Kitagawa, H.; Kawabata, S.; Taube, J.M.; Yao, S.; et al. Control of PD-L1 Expression by Oncogenic Activation of the AKT-MTOR Pathway in Non-Small Cell Lung Cancer. Cancer Res. 2016, 76, 227-238. [CrossRef] [PubMed]

130. Abu-Eid, R.; Samara, R.N.; Ozbun, L.; Abdalla, M.Y.; Berzofsky, J.A.; Friedman, K.M.; Mkrtichyan, M.; Khleif, S.N. Selective Inhibition of Regulatory T Cells by Targeting the PI3K-Akt Pathway. Cancer Immunol. Res. 2014, 2, 1080-1089. [CrossRef]

131. Kaneda, M.M.; Messer, K.S.; Ralainirina, N.; Li, H.; Leem, C.J.; Gorjestani, S.; Woo, G.; Nguyen, A.V.; Figueiredo, C.C.; Foubert, P.; et al. PI3K $\gamma$ Is a Molecular Switch That Controls Immune Suppression. Nature 2016, 539, 437-442. [CrossRef]

132. Chiappinelli, K.B.; Strissel, P.L.; Desrichard, A.; Li, H.; Henke, C.; Akman, B.; Hein, A.; Rote, N.S.; Cope, L.M.; Snyder, A.; et al. Inhibiting DNA Methylation Causes an Interferon Response in Cancer via DsRNA Including Endogenous Retroviruses. Cell 2015, 162, 974-986. [CrossRef] [PubMed]

133. Peng, D.; Kryczek, I.; Nagarsheth, N.; Zhao, L.; Wei, S.; Wang, W.; Sun, Y.; Zhao, E.; Vatan, L.; Szeliga, W.; et al. Epigenetic Silencing of TH1-Type Chemokines Shapes Tumour Immunity and Immunotherapy. Nature 2015, 527, 249-253. [CrossRef] [PubMed]

134. Kim, K.; Skora, A.D.; Li, Z.; Liu, Q.; Tam, A.J.; Blosser, R.L.; Diaz, L.A.; Papadopoulos, N.; Kinzler, K.W.; Vogelstein, B.; et al. Eradication of Metastatic Mouse Cancers Resistant to Immune Checkpoint Blockade by Suppression of Myeloid-Derived Cells. Proc. Natl. Acad. Sci. USA 2014, 111, 11774-11779. [CrossRef] [PubMed]

135. Gameiro, S.R.; Malamas, A.S.; Tsang, K.Y.; Ferrone, S.; Hodge, J.W. Inhibitors of Histone Deacetylase 1 Reverse the Immune Evasion Phenotype to Enhance T-Cell Mediated Lysis of Prostate and Breast Carcinoma Cells. Oncotarget 2016, 7, 7390-7402. [CrossRef]

136. Tomita, Y.; Lee, M.-J.; Lee, S.; Tomita, S.; Chumsri, S.; Cruickshank, S.; Ordentlich, P.; Trepel, J.B. The Interplay of Epigenetic Therapy and Immunity in Locally Recurrent or Metastatic Estrogen Receptor-Positive Breast Cancer: Correlative Analysis of ENCORE 301, a Randomized, Placebo-Controlled Phase II Trial of Exemestane with or without Entinostat. Oncoimmunology 2016, 5. [CrossRef] [PubMed]

137. Forero, A.; Stroyakovskiy, D.; Cha, E.; Cruickshank, S.; Hasapidis, J.; Meyers, M.L.; Slamon, D.J. Abstract OT2-01-12: ENCORE 602: A Randomized, Placebo-Controlled, Double-Blind, Multicenter Phase 2 Study (with a Phase 1b Lead-in) of Atezolizumab with or without Entinostat in Patients with Advanced Triple Negative Breast Cancer (ATNBC). Cancer Res. 2017, 77, OT2-01-12. [CrossRef] 
138. Schaer, D.A.; Beckmann, R.P.; Dempsey, J.A.; Huber, L.; Forest, A.; Amaladas, N.; Li, Y.; Wang, Y.C.; Rasmussen, E.R.; Chin, D.; et al. The CDK4/6 Inhibitor Abemaciclib Induces a T Cell Inflamed Tumor Microenvironment and Enhances the Efficacy of PD-L1 Checkpoint Blockade. Cell Rep. 2018, 22, 2978-2994. [CrossRef] [PubMed]

139. Hurvitz, S.; Martin, M.; Abad, M.F.; Chan, D.; Rostorfer, R.; Petru, E.; Barriga, S.; Costigan, T.M.; Caldwell, C.W.; Nguyen, T.; et al. Abstract S4-06: Biological Effects of Abemaciclib in a Phase 2 Neoadjuvant Study for Postmenopausal Patients with HR+, HER2Breast Cancer. Cancer Res. 2017, 77, S4-S4-06. [CrossRef]

140. Page, D.B.; Bear, H.; Prabhakaran, S.; Gatti-Mays, M.E.; Thomas, A.; Cobain, E.; McArthur, H.; Balko, J.M.; Gameiro, S.R.; Nanda, R.; et al. Two May Be Better than One: PD-1/PD-L1 Blockade Combination Approaches in Metastatic Breast Cancer. NPJ Breast Cancer 2019, 5, 34. [CrossRef]

141. Das, M.; Law, S. Role of Tumor Microenvironment in Cancer Stem Cell Chemoresistance and Recurrence. Int. J. Biochem. Cell Biol. 2018, 103, 115-124. [CrossRef]

142. Chen, P.; Hsu, W.-H.; Han, J.; Xia, Y.; DePinho, R.A. Cancer Stemness Meets Immunity: From Mechanism to Therapy. Cell Rep. 2021, 34, 108597. [CrossRef] [PubMed]

143. Song, K.; Farzaneh, M. Signaling Pathways Governing Breast Cancer Stem Cells Behavior. Stem Cell Res. Ther. 2021, 12, 245. [CrossRef]

144. Gong, C.; Song, E.; Codogno, P.; Mehrpour, M. The Roles of BECN1 and Autophagy in Cancer Are Context Dependent. Autophagy 2012, 8, 1853-1855. [CrossRef] [PubMed]

145. Kumar, B.; Ahmad, R.; Sharma, S.; Gowrikumar, S.; Primeaux, M.; Rana, S.; Natarajan, A.; Oupicky, D.; Hopkins, C.R.; Dhawan, P.; et al. PIK3C3 Inhibition Promotes Sensitivity to Colon Cancer Therapy by Inhibiting Cancer Stem Cells. Cancers 2021, 13, 2168. [CrossRef] [PubMed]

146. Cocco, S.; Leone, A.; Piezzo, M.; Caputo, R.; Di Lauro, V.; Di Rella, F.; Fusco, G.; Capozzi, M.; di Gioia, G.; Budillon, A.; et al. Targeting Autophagy in Breast Cancer. Int. J. Mol. Sci. 2020, 21, 7836. [CrossRef] [PubMed]

147. Janji, B.; Hasmim, M.; Parpal, S.; De Milito, A.; Berchem, G.; Noman, M.Z. Lighting up the Fire in Cold Tumors to Improve Cancer Immunotherapy by Blocking the Activity of the Autophagy-Related Protein PIK3C3/VPS34. Autophagy 2020, 16, $2110-2111$. [CrossRef] [PubMed]

148. Thorburn, A.; Towers, C.G. Enhancing Anti-Tumor Immunity by Autophagy Inhibition. Nat. Cancer 2021, 2, 484-486. [CrossRef]

149. Bareche, Y.; Buisseret, L.; Gruosso, T.; Girard, E.; Venet, D.; Dupont, F.; Desmedt, C.; Larsimont, D.; Park, M.; Rothé, F.; et al. Unraveling Triple-Negative Breast Cancer Tumor Microenvironment Heterogeneity: Towards an Optimized Treatment Approach. J. Natl. Cancer Inst. 2020, 112, 708-719. [CrossRef]

150. Jiang, H.; Hegde, S.; DeNardo, D.G. Tumor-Associated Fibrosis as a Regulator of Tumor Immunity and Response to Immunotherapy. Cancer Immunol. Immunother. 2017, 66, 1037-1048. [CrossRef]

151. Yang, L.; Pang, Y.; Moses, H.L. TGF- $\beta$ and Immune Cells: An Important Regulatory Axis in the Tumor Microenvironment and Progression. Trends Immunol. 2010, 31, 220-227. [CrossRef] [PubMed]

152. Tauriello, D.V.F.; Palomo-Ponce, S.; Stork, D.; Berenguer-Llergo, A.; Badia-Ramentol, J.; Iglesias, M.; Sevillano, M.; Ibiza, S.; Cañellas, A.; Hernando-Momblona, X.; et al. TGF $\beta$ Drives Immune Evasion in Genetically Reconstituted Colon Cancer Metastasis. Nature 2018, 554, 538-543. [CrossRef] [PubMed]

153. Holmgaard, R.B.; Schaer, D.A.; Li, Y.; Castaneda, S.P.; Murphy, M.Y.; Xu, X.; Inigo, I.; Dobkin, J.; Manro, J.R.; Iversen, P.W.; et al. Targeting the TGF $\beta$ Pathway with Galunisertib, a TGF $\beta$ RI Small Molecule Inhibitor, Promotes Anti-Tumor Immunity Leading to Durable, Complete Responses, as Monotherapy and in Combination with Checkpoint Blockade. J. Immunother. Cancer $2018,6,47$. [CrossRef] [PubMed]

154. Bhola, N.E.; Balko, J.M.; Dugger, T.C.; Kuba, M.G.; Sánchez, V.; Sanders, M.; Stanford, J.; Cook, R.S.; Arteaga, C.L. TGF$\beta$ Inhibition Enhances Chemotherapy Action against Triple-Negative Breast Cancer. J. Clin. Investig. 2013, 123, 1348-1358. [CrossRef] [PubMed]

155. Mariathasan, S.; Turley, S.J.; Nickles, D.; Castiglioni, A.; Yuen, K.; Wang, Y.; Kadel, E.E.; Koeppen, H.; Astarita, J.L.; Cubas, R.; et al. TGF $\beta$ Attenuates Tumour Response to PD-L1 Blockade by Contributing to Exclusion of T Cells. Nature 2018, 554, 544-548. [CrossRef] [PubMed]

156. Formenti, S.C.; Lee, P.; Adams, S.; Goldberg, J.D.; Li, X.; Xie, M.W.; Ratikan, J.A.; Felix, C.; Hwang, L.; Faull, K.F.; et al. Focal Irradiation And Systemic Transforming Growth Factor $\beta$ Blockade in Metastatic Breast Cancer. Clin. Cancer Res. 2018, 24, 2493-2504. [CrossRef] [PubMed]

157. Lan, Y.; Zhang, D.; Xu, C.; Hance, K.W.; Marelli, B.; Qi, J.; Yu, H.; Qin, G.; Sircar, A.; Hernández, V.M.; et al. Enhanced Preclinical Antitumor Activity of M7824, a Bifunctional Fusion Protein Simultaneously Targeting PD-L1 and TGF- $\beta$. Sci. Transl. Med. 2018, 10. [CrossRef] [PubMed]

158. Lugano, R.; Ramachandran, M.; Dimberg, A. Tumor Angiogenesis: Causes, Consequences, Challenges and Opportunities. Cell. Mol. Life Sci. 2020, 77, 1745-1770. [CrossRef]

159. Madu, C.O.; Wang, S.; Madu, C.O.; Lu, Y. Angiogenesis in Breast Cancer Progression, Diagnosis, and Treatment. J. Cancer 2020, 11, 4474-4494. [CrossRef]

160. Lee, W.S.; Yang, H.; Chon, H.J.; Kim, C. Combination of Anti-Angiogenic Therapy and Immune Checkpoint Blockade Normalizes Vascular-Immune Crosstalk to Potentiate Cancer Immunity. Exp. Mol. Med. 2020, 52, 1475-1485. [CrossRef] [PubMed] 
161. De Aguiar, R.B.; de Moraes, J.Z. Exploring the Immunological Mechanisms Underlying the Anti-Vascular Endothelial Growth Factor Activity in Tumors. Front. Immunol. 2019, 10, 1023. [CrossRef] [PubMed]

162. Schmittnaegel, M.; Rigamonti, N.; Kadioglu, E.; Cassará, A.; Wyser Rmili, C.; Kiialainen, A.; Kienast, Y.; Mueller, H.-J.; Ooi, C.-H.; Laoui, D.; et al. Dual Angiopoietin-2 and VEGFA Inhibition Elicits Antitumor Immunity That Is Enhanced by PD-1 Checkpoint Blockade. Sci. Transl. Med. 2017, 9, eaak9670. [CrossRef] [PubMed]

163. Yi, M.; Jiao, D.; Qin, S.; Chu, Q.; Wu, K.; Li, A. Synergistic Effect of Immune Checkpoint Blockade and Anti-Angiogenesis in Cancer Treatment. Mol. Cancer 2019, 18, 60. [CrossRef] [PubMed]

164. Zacharakis, N.; Chinnasamy, H.; Black, M.; Xu, H.; Lu, Y.-C.; Zheng, Z.; Pasetto, A.; Langhan, M.; Shelton, T.; Prickett, T.; et al. Immune Recognition of Somatic Mutations Leading to Complete Durable Regression in Metastatic Breast Cancer. Nat. Med. 2018, 24, 724-730. [CrossRef] [PubMed]

165. Dees, S.; Ganesan, R.; Singh, S.; Grewal, I.S. Emerging CAR-T Cell Therapy for the Treatment of Triple-Negative Breast Cancer. Mol. Cancer 2020, 19, 2409-2421. [CrossRef] [PubMed]

166. Han, H.H.; Diab, S.; Alemany, C.; Basho, R.; Brown-Glaberman, U.; Meisel, J.; Pluard, T.; Cortes, J.; Dillon, P.; Ettl, J.; et al. Abstract PD1-06: Open Label Phase 1b/2 Study of Ladiratuzumab Vedotin in Combination with Pembrolizumab for First-Line Treatment of Patients with Unresectable Locally-Advanced or Metastatic Triple-Negative Breast Cancer. Cancer Res. 2020, 80, PD1-06. 